

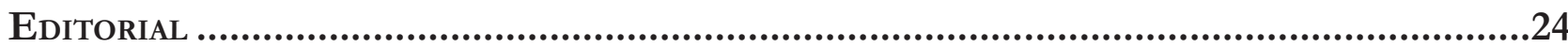

O Direito na fronteira da razão: Psicologia, neurociência e economia comportamental................... 24 Patrícia Perrone Campos Mello e Sergio Nojiri

I. NeURodireito: COGNIÇão, EMOÇÃo, JUÍZOS MORAIS E CIÊNCIA ..........................................26

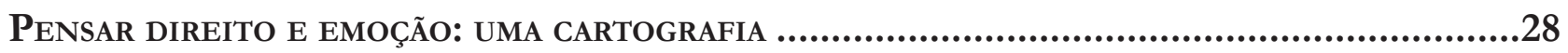

Nevita Maria Pessoa de Aquino Franca Luna

Neurodireito: o início, o fim E O MEIO

Carlos Marden e Leonardo Martins Wykrota

ENSAIO JURÍDICO SOBRE A RACIONALIDADE HUMANA: MAIORES, CAPAZES E IRRACIONAIS

André Perin Schmidt Neto e Eugênio Facchini Neto

DIVERGÊNCIAS DE PRINCÍPIO: ARGUMENTOS JURÍDICOS E MORAIS EM UM CENÁRIO DE DESACORDOS SOCIAIS

André Matos de Almeida Oliveira, Pâmela de Rezende Côrtes e Leonardo Martins Wykrota

CONSILIÊNCIA E A POSSIBILIDADE DO NEURODIREITO: DA DESCONFIANÇA À RECONCILIAÇÃO DISCIPLINAR.....

Thaís de Bessa Gontijo de Oliveira e Renato César Cardoso

MODELOS DE MORALIDADE

Molly J. Crockett

A INFELIZ BUSCA POR FELICIDADE No DiREITo

Úrsula Simões da Costa Cunha Vasconcellost, Noel Struchiner e Ivar Hannikainen

Além da liberdade: PersPeCtivas Em Nietzsche.

Lucas Costa de Oliveira

A mediaÇão de CONFlitos SOb a PERSPECTIVA do DESENVOLVIMENTO HUMANO: AS CONTRIBUIÇÕES DA PSICOLOGIA POSITIVA

Simone de Biazzi Ávila Batista da Silveira e Deise Brião Ferraz

Neuroimagiologia e aValiação de ResPonsabilidade

Nicole A. Vincent 
ANÁLISE CRÍTICA DA ORIENTAÇÃO DE CIDADÃOS COMO MÉTODO PARA OTIMIZAR DECISÕES PÚBLICAS POR MEIO DA TÉCNICA NUDGE.

Luciana Cristina Souza, Karen Tobias França Ramos e Sônia Carolina Romão Viana Perdigão

Políticas públicas e o deVer de monitoramento: “LEVANdo os Direitos A SÉrio". .252 Ana Paula de Barcellos

Nudges E POLÍticas PÚblicas: uM MECANISMO DE COMBATE AO TRABALHO EM CONDIÇÃo ANÁLOGA À DE ESCRAVO .267

Amanda Carolina Souza Silva, Débhora Renata Nunes Rodrigues e Saul Duarte Tibaldi

REDUZINDO A TRIBUTAÇÃO COGNITIVA: LIÇÕES COMPORTAMENTAIS PARA A DIMINUIÇÃO DOS EFEITOS PSICOLÓGICOS ADVERSOS DA POBREZA.............................................................288 Leandro Novais e Silva, Luiz Felipe Drummond Teixeira, Gabriel Salgueiro Soares e Otávio Augusto Andrade Santos

Políticas PÚBLICAS EM SUICÍDIO: DO PATERNALISMO CLÁSSICO AO PATERNALISMO LIBERTÁRIO E NUDGING

Davi de Paiva Costa Tangerino, Gabriel Cabral e Henrique Olive

Nudges COMO POLÍticA PÚbliCA PARA AUMENTAR O ESCASSO NÚMERO DE DOADORES DE ÓRGÃos PARA TRANSPLANTE

Roberta Marina Cioatto e Adriana de Alencar Gomes Pinheiro

Os PROGRAMAS DE INTEGRIDADE PARA CONTRATAÇÃO COM A ADMINISTRAÇÃO PÚBLICA ESTADUAL: NUDGE OU OBRIGAÇÃo LEGAL? UM OLHAR SOBRE AS DUAS PERSPECTIVAS .386

Cíntia Muniz Rebouças de Alencar Araripe e Raquel Cavalcanti Ramos Machado

Paternalismo libertário e Proteção JURídica do AMbiente: POR QUe PROTEger o AMBIENTE TAMBÉM DEVE SER PROTEGER AS LIBERDADES?

Mariana Carvalho Victor Coelho e Patryck de Araujo Ayala

Políticas PÚblicas baseadas EM EVIdÊNCIAS COMPORTAMENTAIS: REFLEXões A PARTIR do Projeto de Lei 488/2017 do Senado

Pâmela de Rezende Côrtes, André Matos de Almeida Oliveira e Fabiano Teodoro de Rezende Lara

III. ECONOMIA COMPORTAMENTAL: VIESES COGNITIVOS E POLÍTICAS PÚBLICAS .455

ECONOMIA COMPORTAMENTAL E DIREITO: A RACIONALIDADE EM MUDANÇA Marcia Carla Pereira Ribeiro e Victor Hugo Domingues

VIESES COGNITIVOS E DESENHO DE POLÍTICAS PÚBLICAS 
A neurociênCia da moralidade na tomada de DeCisões Jurídicas Complexas e No DESENHO DE POLÍTICAS PÚBLICAS

Erik Navarro Wolkart

Desvio de CARÁter ou SIMPLESMENTE HUMANO? ECONOMIA COMPORTAMENTAL APLICADA AO COMPORTAMENTO DESONESTO

Diana Orghian, Gabriel Cabral, André Pinto e Alessandra Fontana

Políticas Públicas e a ConcretizaÇão de direitos sociais: TOMAdA DE DECisão, ARQUITETURA DE ESCOLHAS E EFETIVIDADE

Ana Elizabeth Neirão Reymão e Ricardo dos Santos Caçapietra

BEHAVIORAL ECONOMICS E DIREITO DO CONSUMIDOR: NOVAS PERSPECTIVAS PARA O ENFRENTAMENTO DO SUPERENDIVIDAMENTO .568

Samir Alves Daura

A EDUCAÇÃo FORMAL PARA O CONSUMO É GARANTIA PARA UMA PRESENÇA REFLETIDA DO CONSUMIDOR NO MERCADO? UMA ANÁLISE COM BASE NA BEHAVIORAL LAW AND ECONOMICS (ECONOMIA COMPORTAMENTAL) 600

Marcia Carla Pereira Ribeiro e Edson Mitsuo Tiujo

LIBET, DETERMINISMO E CONSUMO: AS INFLUÊNCIAS DO MARKETING E A RELEVÂNCIA DA DELIBERAÇÃo CONSCIENTE NA SUPERAÇÃo CONDICIONAL DE HÁBITOS DE CONSUMO PERIGOSOS616 Émilien Vilas Boas Reis e Leonardo Cordeiro de Gusmão

CiÊNCIA DO DIREITO TRIBUTÁRIO, ECONOMIA COMPORTAMENTAL E EXTRAFISCALIDADE. .640 Hugo de Brito Machado Segundo

IV. CoMportamento JUdiCiAL: INFLUÊNCIA DE FATORES EXTRAJURÍDicos .660

FATORES METAPROCESSUAIS E SUAS INFLUÊNCIAS PARA A FORMAÇÃo DA DECISÃo JUDICIAL .662 Rogério Roberto Gonçalves de Abreu, Lúcio Grassi de Gouveia e Virgínia Colares

“A VIDA COMO ELA É": COMPORTAMENTO ESTRATÉGICO NAS CORTES Patrícia Perrone Campos Mello

A COMPOSIÇÃo do ÓRGão COLEGIAdo E SEUS EFEITOS NA TOMADA DE DECISÃo .720 André Garcia Leão Reis Valadares

Das 11 ilhas ao centro do arquipélago: os superpoderes do Presidente do STF DURANTE O RECESSO JUDICIAL E FÉRIAS .741 José Mário Wanderley Gomes Neto e Flávia Danielle Santiago Lima 
RAZÃo, EMOÇÃo E DELIBERAÇÃO: AS ADEQUAÇÕES REgIMENTAIS do SUPERIOR TribUNAL DE JUSTIÇA PARA A FORMAÇÃo DE PRECEDENTES EFICAZES

Peter Panutto e Lana Olivi Chaim

Heurística de ancoragem e fiXaÇÃo de danos morais em JUizados especiais Cíveis no Rio DE JANEIRO: UMA NOVA ANÁLISE 778

Fernando Leal e Leandro Molhano Ribeiro

LA PROTECCIÓN DE LOS DERECHOS POLÍTICOS FRENTE A LAS FUNCIONES DISCIPLINARIAS DE LAS AUTORIDADES ADMINISTRATIVAS: SUBSIDIARIEDAD Y DEFERENCIA EN EL SISTEMA INTERAMERICANO DE DERECHOS HUMANOS Jorge Ernesto Roa Roa

V. A influênCia do gÊNERo no PROCESSO DECisório JUdiCial

Como os Juízes decidem os Casos de estupro? ANALISANDo SENTENÇAS SOb A PERSPECTIVA DE VIESES E ESTEREÓTIPOS DE GÊNERO 826 Gabriela Perissinotto de Almeida e Sérgio Nojiri

GÊNERO E COMPORTAMENTO JUDICIAL NO SUPREMO TRIBUNAL FEDERAL: OS MINISTROS CONFIAM MENOS EM RELATORAS MULHERES?

Juliana Cesario Alvim Gomes, Rafaela Nogueira e Diego Werneck Arguelhes

Hércules, Hermes e a Pequena Sereia: uma reflexão sobre estereótipos de gênero, SUBPRESENTAÇÃo DAS MULHERES NOS TRIBUNAIS E (I)LEGITIMIDADE DEMOCRÁTICA DO PODER JUDICIÁRIO. .878 Jane Reis Gonçalves Pereira e Renan Medeiros de Oliveira

Prisão Cautelar de gestantes: análise do Fundamento filosófico da decisão do Habeas CoRpus N. 143.641 912

Artur César Souza e Giovania Tatibana de Souza

VI. Neurodireito APlicado ao direito E Ao Processo PENAL....................................926

CÉREbros QUe PUNEM: UMA REVISÃo CRÍTICA DA NEURoCIÊNCIA DA PUNIÇÃo .....................928 Ricardo de Lins e Horta

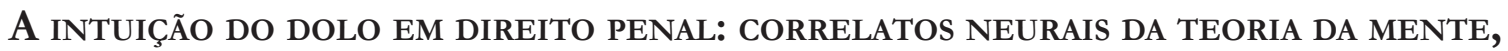
RACIOCÍNIO INDUTIVO E A GARANTIA DA CONVICÇÃO JUSTIFICADA. .946 Thiago Dias de Matos Diniz e Renato César Cardoso

As COMUNIDADES EPISTÊMICAS PENAIS E A PRODUÇÃo LEGISLATIVA EM MATÉRIA CRIMINAL..... 961 Stéphane Enguéléguélé 
DELINQUÊNCIA JUVENIL: RELAÇÕES ENTRE DESENVOLVIMENTO, FUNÇÕES EXECUTIVAS E COMPORTAMENTO SOCIAL NA ADOLESCÊNCIA .

André Vilela Komatsu, Rafaelle CS Costa e Marina Rezende Bazon

Límites TEMPORALES A LAS PENAS PRIVATIVAS DE LIBERTAD ATENDIENDO AL DESARROLLO PSICOSOCIAL.

Silvio Cuneo Nash

NEURolaw E AS PERSPECTIVAS PARA UMA ANÁLISE OBJETIVA DO COMPORTAMENTO SUGESTIONADO: REPERCUSSÃO DAS FALSAS MEMÓRIAS NA ESFERA PENAL

Mariana Dionísio de Andrade, Marina Andrade Cartaxo e Rafael Gonçalves Mota

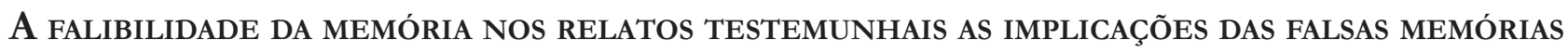
NO CONTEXTO DOS CRIMES CONTRA A DIGNIDADE SEXUAL

Caroline Navas Viana

A (IR)REPETIBILIDADE dA PROVA PENAL DEPENDENTE DA MEMÓRIA: UMA DisCUSSÃo COM BASE NA PSICOLOGIA DO TESTEMUNHO. 1058

William Weber Cecconello, Gustavo Noronha de Avila e Lilian Milnitsky Stein 


\title{
Políticas públicas baseadas em evidências comportamentais: reflexões a partir do Projeto de Lei 488/2017 do Senado*
}

\section{Behavioral evidence-based policy: reflections on Senate Bill 488/2017}

\author{
Pâmela de Rezende Côrtes** \\ André Matos de Almeida Oliveira*** \\ Fabiano Teodoro de Rezende Lara****
}

* Recebido em 31/05/2018

Aprovado em 01/08/2018

** Doutoranda em Direito pela Universidade Federal de Minas Gerais, Bolsista CAPES. Mestre em Direito e Bacharel em Ciências do Estado pela UFMG. Coordenadora do Projeto de Extensão em Políticas Públicas Baseadas em Evidências. Membro do Grupo de Estudos em Neuroética e Neurodireito. E-mail: pamela.recortes@gmail.com

*** Mestrando em Direito pela Universidade Federal de Minas Gerais, Bolsista CAPES. Bacharel em Direito pela UFMG. Monitor do Grupo de Estudos em Neuroética e Neurodireito. E-mail: andrematosalmeida@hotmail.com

**** Doutor em Direito pela UFMG. Professor Adjunto do Departamento de Direito Público junto à Graduação, Mestrado e Doutorado em Direito da Faculdade de Direito da UFMG e do IBMEC. Advogado. E-mail: fabiano@fabianolara.com.br

\section{Resumo}

O objetivo deste artigo é avaliar se o Projeto de Lei Complementar 488/2017 do Senado (PLS 488/2017) pode aumentar a permeabilidade dos criadores de políticas públicas ao uso de evidências, sobretudo comportamentais. A hipótese é a de que a regulação proposta pode aumentar o uso de evidências na proposição de políticas públicas, ao recomendar mecanismos de controle, de avaliação e atenção ao texto legislativo que se proponha a instituir uma política pública. A metodologia adotada será a revisão bibliográfica dos conceitos relevantes e das evidências comportamentais, assim como uma descrição e análise crítica do texto legislativo estudado. Começamos por apresentar o PLS 488/2017, sua proposta de alteração legislativa e as razões para a sua proposição. Em seguida, discutimos o que pode ser considerado uma política pública, tanto da perspectiva acadêmica quanto da perspectiva do projeto de lei, comparando as definições apresentadas. Posteriormente, abordamos o movimento de políticas públicas baseadas em evidências, expondo seu surgimento, as formas de se compreender o uso de evidências nas políticas, algumas críticas e estratégias importantes para respondê-las. Passamos para o uso de evidências comportamentais nas políticas públicas, primeiro abordando os nudges, que são um tipo de política comportamental relevante no debate acadêmico, e, depois, defendendo um uso mais amplo das evidências comportamentais nos diversos estágios das políticas públicas. Por meio da revisão de literatura, percebemos que o uso de evidências nas políticas pode aumentar a efetividade das políticas e melhorar a atuação do Estado. Por meio da análise crítica do PLS 488/2017, concluímos que ele abre espaço para o uso de evidências comportamentais em alguns de seus dispositivos, sobretudo na tomada de decisão e na implementação da política, e que o projeto pode ser visto como um estímulo ao diálogo entre os criadores de políticas e os coletores de dados e evidências comportamentais relevantes.

Palavras-chave: Políticas públicas baseadas em evidências. Ciências comportamentais. Projeto de Lei 488/2017 do Senado. Regulação de políticas públicas. 


\section{Abstract}

This paper aims to investigate whether Senate Bill 488/2017 can make policy-makers more receptive to the use evidences, especially behavioral ones. Our hypothesis is that the directive in the bill can increase the use of evidences in public policy propositions, in recommending control mechanisms and methods of evaluation of laws that creates new public policies. We will do the analysis by means of a literature review of the relevant concepts we are using and by a critical evaluation of the legislative text we are approaching. The structure of the text is as follows: we start by introducing the bill, its proposed legislative amendment and the reasons for its proposal. Next, we discuss what is a public policy, both from the academic point of view and from what the text of the bill tells us. Then, we approach the evidence-based movement, talking about its emergence, the multiple ways to use evidence in policies, some criticisms of it, and ways to answer them. The next move is the use of behavioral evidence on policies; we first present the nudges, an important type of behavioral policy in academia, and then expand the use of evidences to other stages of policies. We conclude that the use of behavioral evidence can increase the policy's effectiveness and improve the performance of the government, and that the bill, in some of its directives, paves the way for the use of behavioral evidence. The bill can be seen as an incentive for the dialogue and interchange between public policy-makers and researchers collecting relevant behavioral data.

Keywords: Behavioral-evidence-based policy. Behavioral sciences. Senate bill 488/2017. Policies regulation.

\section{INTRODUÇÃO}

Esse artigo pretende avaliar como o Projeto de Lei 488/2017, de iniciativa do Senado (PLS 488/2017), pode aumentar o uso de evidências comportamentais por parte dos criadores de políticas públicas no Brasil.

Para fazer isso, o primeiro passo será fazer uma análise mais ampla do projeto de lei, explicitando seus objetivos e seu âmbito normativo. O projeto de lei busca regular novas proposições de políticas públicas, determinando critérios tanto para a produção de projetos (como vir acompanhado de uma Análise de Impacto Legislativo, AIL) quanto sobre o conteúdo das políticas, exigindo a observância de critérios como economicidade, efetividade, eficácia e eficiência.

Como o foco do projeto são as políticas públicas, a seguir faremos uma breve análise teórica delas e de suas abordagens. A análise, avaliação e controle das políticas públicas são temas cada vez mais relevantes nacional e internacionalmente. As razões para esse interesse, especialmente em países da América Latina, são o aumento do controle dos gastos públicos, a visão do papel dos governos de forma mais restritiva e fiscalmente equilibrada e a dificuldade desses países em formar coalizões políticas coesas e capazes de desenhar boas políticas públicas ${ }^{1}$.

Esse debate pode assumir diversos matizes teóricos, e esse trabalho partirá de uma perspectiva de políticas públicas que sejam baseadas em evidências. O próximo passo, portanto, será o de apresentar essa perspectiva, que tem ganhado espaço nos debates acadêmicos internacionais ${ }^{2}$, mas que é, ainda, bem tímida no Brasil, com exceção da área de saúde pública.

Especificaremos, então, como as evidências provenientes de ciências comportamentais podem ser úteis nas políticas públicas. Discutiremos os nudges, que são a forma mais consolidada de unir as duas áreas. Concluiremos, por fim, que as evidências das ciências comportamentais podem ser úteis em praticamente qual-

1 SOUZA, Celina. Políticas públicas: uma revisão da literatura. Sociologias, Porto Alegre, ano 8, n. 16, p. 20-45, jul./dez. 2006. p. 20.

2 ARGYROUS, George. Evidence based policy: principles of transparency and accountability. Australian Journal of Public Administration, v. 71, n. 4, p. 457-468, 2012. p. 457. 
quer área em que o poder público possa interferir, ampliando o debate e mostrando como o PLS 488/2017 pode ser usado para inserir essas ciências na produção de políticas públicas no país.

\section{O Projeto de Lel $488 / 2017$ do Senado}

O Projeto de Lei de iniciativa do Senado 488/2017 (PLS 488/2017), que tramita, no tempo da redação deste artigo, na Câmara como Projeto de Lei Complementar do Senado (PLS) 494/2018, estabelece limites e critérios para a proposição de políticas públicas. Em linhas gerais, o projeto de lei visa alterar a Lei Complementar no 95 (LC 95), de 26 de fevereiro de 1998, que "dispõe sobre a elaboração, a alteração e a consolidação das leis" e "estabelece normas para a consolidação dos atos normativos que menciona" 3.

Essa lei complementar foi editada como resposta legislativa ao que é ordenado pelo artigo $\mathrm{n}^{\circ} 59$ da Constituição da República (CR/88), que descreve o processo legislativo brasileiro, e, em seu parágrafo único, afirma que "Lei complementar disporá sobre a elaboração, redação, alteração e consolidação das leis" ${ }^{4}$. Antes da edição dessa lei, muito pouco tinha sido produzido no Brasil em termos de doutrina com relação à produção de leis e de qualidade de técnica legislativa ${ }^{5}$.

A LC 95 tem como objetivo principal estabelecer as normas para produção de leis e demais instrumentos normativos ${ }^{6}$; em sua extensão, determina como deve ser feita a redação de uma lei, qual informação deve ser apresentada em que parte da lei (a epígrafe, a ementa, o preâmbulo, o enunciado, o texto das normas, as disposições transitórias etc.) e como deve ser feita a modificação de uma lei já editada.

A LC 95, juntamente ao Decreto $\mathrm{n}^{\circ}$ 4.176, de 28 de março de 2002, regulamentava a técnica legislativa ou a legística formal no Brasil7. Porém, o Decreto foi revogado no ano de 2018, sendo substituído pelo Decreto $\mathrm{n}^{\circ} 9.191$, de $1^{\circ}$ de novembro de $2017^{8}$, que ainda faz par com a LC 95 na regulamentação da legística formal.

A legística

pode ser definida como saber jurídico que evoluiu a partir de algumas das questões recorrentes na história do direito, vale dizer, a necessidade de uma legislação mais eficaz (no sentido de estar disponível e atuante para a produção de efeitos), o questionamento da lei como o instrumento exclusivo para a consecução de mudanças sociais, a necessidade de democratizar o acesso aos textos legais em todos os níveis?.

3 BRASIL. Lei Complementar n ${ }^{\circ}$ 95, de 26 de fevereiro de 1998. Dispõe sobre a elaboração, a redação, a alteração e a consolidação das leis, conforme determina o parágrafo único do art. 59 da Constituição Federal, e estabelece normas para a consolidação dos atos normativos que menciona. Disponível em: <http://www.planalto.gov.br/ccivil_03/leis/lcp/lcp95.htm>. Acesso em: 25 mar. 2018. 4 BRASIL. Constituição (1988). Constituição da República Federativa do Brasil. Disponível em <http://www.planalto.gov.br/ccivil_03/constituicao/constituicao.htm>. Acesso em: 25 mar. 2018.

5 SALINAS, Natasha Schmitt Caccia. Avaliação Legislativa no Brasil: apontamentos para uma nova agenda de pesquisa sobre o modo de produção das leis. Revista Brasileira de Políticas Públicas, Brasília, v. 3, n. 2, p. 243, 2013.

6 Artigo $1^{\circ}$, parágrafo único da LC 95 afirma: "As disposições desta Lei Complementar aplicam-se, ainda, às medidas provisórias e demais atos normativos referidos no art. 59 da Constituição Federal, bem como, no que couber, aos decretos e aos demais atos de regulamentação expedidos por órgãos do Poder Executivo." BRASIL. Lei Complementar n 95, de 26 de fevereiro de 1998. Dispõe sobre a elaboração, a redação, a alteração e a consolidação das leis, conforme determina o parágrafo único do art. 59 da Constituição Federal, e estabelece normas para a consolidação dos atos normativos que menciona. Disponível em: <http://www.planalto.gov.br/ ccivil_03/leis/lcp/lcp95.htm>. Acesso em: 25 mar. 2018.

7 SALINAS, Natasha Schmitt Caccia. Avaliação Legislativa no Brasil: apontamentos para uma nova agenda de pesquisa sobre o modo de produção das leis. Revista Brasileira de Politicas Públicas, Brasília, v. 3, n. 2, p. 244, 2013.

8 BRASIL. Decreto $n^{\circ}$ 9.191, de $1^{\circ}$ de novembro de 2017. Estabelece as normas e as diretrizes para elaboração, redação, alteração, consolidação e encaminhamento de propostas de atos normativos ao Presidente da República pelos Ministros de Estado. Disponível em: < http://www.planalto.gov.br/CCIVil_03/_Ato2015-2018/2017/Decreto/D9191.htm\#art60>. Acesso em: 26 jul. 2018.

9 SOARES, Fabiana de Menezes. Legística e desenvolvimento: a qualidade da lei no quadro da otimização de uma melhor legislação. Revista da Faculdade de Direito da UFMG, Belo Horizonte, n. 50, p. 124-142, jan./jul. 2007, p. 125. Disponível em: <https:// www.direito.ufmg.br/revista/articles/31.pdf>. Acesso em: 27 jul. 2018. 
A legística formal, por sua vez, "atua sobre a otimização do círculo de comunicação legislativa e fornece princípios destinados à melhoria da compreensão e do acesso aos textos legislativos" ${ }^{10}$.

Embora a inobservância da técnica prevista na lei não seja suficiente para declarar uma lei inconstitucional, ainda assim parece importante que os legisladores e demais criadores de atos normativos tentem "empreender esforços para incorporar seus preceitos em prol de uma produção normativa que venha a cumprir com maior eficiência suas finalidades, sob pena de se criar mais conflitos do que aqueles que se pretendeu apaziguar" "11. Infelizmente, pode-se dizer que a própria LC 95 ignorou suas recomendações, já que "seu próprio texto contradiz os seus fins e artigos que fixaram prazo para a consolidação foram revogados". O mesmo pode-se dizer do extinto Decreto nº 4.176 de 2002, que "prevê um instrumento para avaliação de impacto dos atos normativos", mas vinha "sendo ignorado pelo executivo, contraditoriamente pródigo na sua atividade legislativa" ${ }^{12}$. O Decreto no 9.191 de 2017 é, ainda, muito recente para ser avaliado em termos de efetividade, mas não há razões para crer que ele será muito mais efetivo que seu antecessor.

O projeto de lei a ser avaliado, PLS 488/2017, por sua vez, tem como objetivo inserir um novo capítulo na LC 95, que se intitulará: “Capítulo III-A Dos Projetos De Lei que instituam Políticas Públicas”. Seu objetivo geral é o de "estabelecer normas e diretrizes para encaminhamento de proposições legislativas que instituam políticas públicas, propiciando melhor responsabilidade gerencial na Administração Pública" ${ }^{13}$. Se o PLS 488/17 for aprovado nos termos atuais, serão inseridos três novos artigos na LC 95: 17-A, 17-B e $17-C^{14}$.

10 SOARES, Fabiana de Menezes. Legística e desenvolvimento: a qualidade da lei no quadro da otimização de uma melhor legislação. Revista da Faculdade de Direito da UFMG, Belo Horizonte, n. 50, p. 124-142, jan./jul. 2007. p. 126. Disponível em: <https:// www.direito.ufmg.br/revista/articles/31.pdf>. Acesso em: 27 jul . 2018.

11 ALVAREZ, Adela Duarte. Elaboração Legislativa: aspectos gerais. Revista do Parlamento Paulista - RPP, São Paulo, v.2, n.3, p.112123, jul./dez. 2012. p. 122.

12 SOARES, Fabiana de Menezes. Legística e desenvolvimento: a qualidade da lei no quadro da otimização de uma melhor legislação. Revista da Faculdade de Direito da UFMG, Belo Horizonte, n. 50, p. 124-142, jan./jul. 2007. p. 139-140. Disponível em: <https:// www.direito.ufmg.br/revista/articles/31.pdf>. Acesso em: 27 jul. 2018.

13 BRASIL. Projeto de Lei Complementar do Senado no 488 de 2017 - Texto final. Acrescenta dispositivos à Lei Complementar $\mathrm{n}^{\circ}$ 95, de 26 de fevereiro de 1998, com o intuito de estabelecer normas e diretrizes para encaminhamento de proposições legislativas que instituam políticas públicas, propiciando melhor responsabilidade gerencial na Administração Pública. Disponível em: <https://legis.senado.leg.br/sdleg-getter/documento?dm=7326614\&disposition=inline> Acesso em: 15 maio 2018.

14 Essa é a redação atual dos artigos a serem inseridos: "Art. 17-A: Os projetos de lei que instituam políticas públicas serão acompanhados de avaliação prévia de impacto legislativo, com o intuito de garantir a economicidade, a efetividade, a eficácia e a eficiência das ações públicas. $\$ 1^{\circ}$ : Para fins deste artigo, entende-se por: I - política pública, a mobilização político-administrativa para articular e alocar recursos e esforços para tentar solucionar dado problema coletivo; II - economicidade, a minimização dos custos dos recursos utilizados na consecução de uma atividade, sem comprometimento dos padrões de qualidade; III - efetividade, o alcance dos resultados pretendidos, a médio e longo prazo; IV - eficácia, o alcance das metas programadas e cumprimento dos objetivos imediatos; e V - eficiência, a menor relação entre os custos impostos pela lei e os benefícios oriundos dela. Art. 17-B: Na concepção das políticas públicas, de forma a incrementar a capacidade de governança e gestão da Administração Pública, devem ser definidos: I - os responsáveis pela coordenação e articulação das ações concernentes à política; II - a atuação dos diversos órgãos, instituições e esferas de governo envolvidos, garantindo a coerência e a sinergia da ação estatal nas dimensões econômica, social e ambiental e incentivando a participação social no processo decisório das políticas públicas; III - as competências das principais partes envolvidas na política pública, incluindo os respectivos objetivos, papéis, responsabilidades, recursos e obrigações; IV - o grau de focalização ou universalização da política pública, considerando as necessidades do público-alvo, bem como os recursos disponíveis; V - a abordagem para tratar a solução de conflitos, bem como estabelecer formas de revisão, fixando a periodicidade da avaliação de desempenho da política com o intuito de se promover ajustes que se façam necessários; VI - plano de gestão de riscos com a identificação dos principais problemas que podem surgir juntamente com as respectivas medidas mitigadoras para tratar esses riscos; VII - os marcos de verificação, indicadores-chave e metas para os principais objetivos que permitam a medição do progresso e facilitem a identificação de interdependências e obstáculos; VIII - a formalização dos processos decisórios correlatos, incluindo o registro da motivação e do conjunto de evidências que embasam a escolha política; IX - mecanismos e procedimentos internos de integridade e auditoria na aplicação efetiva de códigos de ética e de conduta, bem como de formalização de instrumentos de transparência; e X - plano de gestão documental, com o intuito de preservar a memória unificada de todas as fases da política pública desde a sua concepção. Parágrafo único: O órgão responsável pela condução da política deverá publicar, para conhecimento de todas as partes interessadas, a estrutura de governança vigente na política pública. Art. 17-C: A avaliação prévia do impacto legislativo, consoante o que dispõe o art. 17-A, conterá: I - parecer conclusivo sobre a constitucionalidade, a juridicidade e a regularidade formal do ato normativo proposto; e II - notas explicativas que demonstrem, no que for pertinente, a economicidade, a efetividade, a eficácia e a eficiência das medidas constantes do projeto, contendo: a) síntese qualitativa e quantitativa do problema ou da situação 
O PLS 488/2017 é de autoria do Senador Federal Roberto Muniz, do Partido Progressista, PP, do estado da Bahia. Na justificação do projeto, porém, são apontados outros atores que participaram da elaboração do documento. Assim, faz alusão a discussões com o Tribunal de Contas da União, reconhece a participação da Consultoria Legislativa do Senado e as manifestações de técnicos da Câmara dos Deputados e do IPEA ${ }^{15}$.

O Projeto de Lei parece estar em sintonia, de alguma forma, com o documento produzido pela Casa Civil da Presidência, chamado: "Avaliação de políticas públicas: guia prático de análise ex ante" (feita antes), publicado nesse ano de 2018. Esse guia é uma "medida prática de adoção de mecanismo de liderança e estratégia", que busca "direcionar ações para a busca de resultados para a sociedade, encontrando soluções tempestivas e inovadoras para lidar com a limitação de recursos e com as mudanças de prioridades" e, de forma mais direta, direcionar a atenção para custos e benefícios quando algum ator político for propor, expandir ou aperfeiçoar uma política pública ${ }^{16}$.

O projeto aponta algumas razões para a sua proposição. Dentre elas, fala explicitamente do "amadurecimento democrático da sociedade brasileira", que demanda cada vez mais controle sobre a atuação estatal, sobretudo quanto à "efetividade das ações que empreende visando à melhora da realidade socioeconômica" 17.

Considerando-se que o IPEA foi diretamente citado como parte ativa no processo de construção do projeto de lei, é razoável concluir que as produções do guia e do projeto tenham se beneficiado dos mesmos debates e inquietações dos pesquisadores do instituto. Uma das razões fundamentais para a produção do guia é a edição da Emenda Constitucional no 95/2016 (EC 95), que estabelece um Novo Regime Fiscal e ficou conhecida como a "PEC dos gastos públicos" ou ainda "PEC do fim do mundo". A EC 95 limita os gastos públicos por "vinte exercícios financeiros", ou seja, 20 anos $^{18}$. Essa limitação orçamentária de 20 anos aumentaria a "necessidade de um debate mais qualificado sobre a priorização de políticas públicas e as decisões alocativas do orçamento" ${ }^{19}$. Esse debate qualificado parece ter necessidade ainda maior quando se nota que, em vários casos, as políticas públicas do país não atingem os resultados esperados. Relatório recente do IPEA estima que, desde o mandato de Lula, o governo brasileiro deu subsídios de R $\$ 173$ bilhões a programas sem efeitos significativos; dos 20 programas analisados, 4 não trouxeram nenhum retorno ${ }^{20}$

Parece-nos, portanto, que a contingência orçamentária despertou no legislativo o interesse em aumentar

que reclama providências; b) objetivos da proposição e sua vinculação com o problema definido; c) alternativas existentes para a solução do problema identificado, com respectiva previsão dos impactos econômicos e sociais, justificando a escolha da solução ou providência contida no projeto proposto, com comparação das análises de custo-benefício global de cada alternativa; d) custos administrativos da solução ou providência contida no projeto proposto, caso a alternativa estabelecida na proposição entre em vigor; e e) indicação da existência de prévia dotação orçamentária ou a fonte de recursos, quando a proposta demandar despesas, e como a ação está enquadrada no Plano Plurianual vigente".

15 BRASIL. Projeto de Lei Complementar do Senado no 488 de 2017 - Texto preliminar. Acrescenta dispositivos à Lei Complementar $\mathrm{n}^{\circ}$ 95, de 26 de fevereiro de 1998, com o intuito de estabelecer normas e diretrizes para encaminhamento de proposições legislativas que instituam políticas públicas, propiciando melhor responsabilidade gerencial na Administração Pública. Disponível em: <https://legis.senado.leg.br/sdleg-getter/documento?dm=7326614\&disposition=inline> Acesso em: 15 maio 2018.

16 BRASIL. Casa Civil da Presidência da República. Avaliação de políticas públicas: guia prático de análise ex ante. Casa Civil da Presidência da República, Instituto de Pesquisa Econômica Aplicada. Brasília: Ipea, 2018. v. 1, p. 7.

17 BRASIL. Projeto de Lei Complementar do Senado no 488 de 2017 - Texto preliminar. Acrescenta dispositivos à Lei Complementar no 95 , de 26 de fevereiro de 1998, com o intuito de estabelecer normas e diretrizes para encaminhamento de proposições legislativas que instituam políticas públicas, propiciando melhor responsabilidade gerencial na Administração Pública. Disponível em: <https:// legis.senado.leg.br/sdleg-getter/documento?dm=7326614\&disposition=inline > Acesso em: 15 maio 2018.

18 BRASIL. Emenda Constitucional no 95, de 15 de dezembro de 2016. Altera o Ato das Disposições Constitucionais Transitórias, para instituir o Novo Regime Fiscal, e dá outras providências. Disponível em: < http://www.planalto.gov.br/ccivil_03/constituicao/ emendas/emc/emc95.htm>. Acesso em: 22 mar. 2018. artigo 106.

19 BRASIL. Casa Civil da Presidência da República. Avaliação de políticas públicas: guia prático de análise ex ante. Casa Civil da Presidência da República, Instituto de Pesquisa Econômica Aplicada. Brasília : Ipea, 2018. v.1. p. 11.

20 WIZIACK, Júlio; PRADO, Maeli. Governo deu R 173 bi em subsídios a programas sem efeitos, diz estudo. São Paulo. Folha de São Paulo. 22 jul. 2018. Disponível em: <https://www1.folha.uol.com.br/mercado/2018/07/governo-deu-r-173-bi-em-subsidiosa-programas-sem-efeitos-diz-estudo.shtml>. Acesso em: 26 jul. 2018. 
o controle dos gastos ou investimentos públicos, e que o estabelecimento de regras para proposição de políticas públicas tenha como objetivo implícito o de aumentar a consciência da finitude do orçamento por parte do agente público. Um objetivo louvável, mas que não precisa da edição de atos normativos que chamem a atenção para o orçamento, já que o controle orçamentário é "o instrumento pelo qual se positiva toda a atividade financeira do Estado, tendo sua sede na Constituição" ${ }^{21}$.

Outra questão interessante suscitada pelo projeto diz respeito à legitimidade do Poder Legislativo como órgão fiscalizador do Poder Executivo. O projeto afirma que o amadurecimento democrático aumenta a necessidade de controle, e afirma que "setores representativos da sociedade" devem se "aparelhar" para acompanhar o "ciclo de políticas públicas", conferindo a si mesmo, ou seja, ao "Congresso Nacional", um papel de destaque. É fato que esse poder é conferido pela própria Constituição, que afirma, em seu artigo 49, que é "da competência exclusiva do Congresso Nacional", e prossegue no inciso X elencando: "fiscalizar e controlar, diretamente, ou por qualquer de suas Casas, os atos do Poder Executivo, incluídos os da administração indireta" 22 .

No entanto, considerando as críticas recentes quanto à estrutura e legitimidade dos poderes, sobretudo no Brasil, resta questionar se esse controle deva ser feito, exclusivamente, pelo Poder Legislativo, ou se já seria possível prever instâncias de controle social ou popular na proposição de políticas públicas. Ao reconhecer-se como "representativo", o Congresso não parece acompanhar as importantes críticas contemporâneas ao seu funcionamento e à sua (in)capacidade de apresentar aos eleitores opções viáveis e ideologicamente consistentes ${ }^{23}$.

Essa crítica se revela, sobretudo, tendo em vista a ineficiência de sua produção legislativa para a solução de problemas do país. Um estudo do Instituto Brasileiro de Planejamento e Tributação revela que, do período que vai da promulgação da Constituição de 88 até setembro de 2016, foram editados 5,4 milhões de textos normativos no Brasil, o que equivale a 769 normas por dia útil24. Essa "hipertrofia legislativa", no entanto, não torna o poder legislativo eficiente aos olhos do cidadão, mas combina-se com a falta de representatividade e leva a crer que a atuação legislativa acontece para privilegiar grupos de interesse capazes de exercer pressão sobre deputados e senadores. Esse excesso também leva a edição de normas cada vez mais vagas com conceitos jurídicos indeterminados, o que abre espaço para discricionariedade judicial e administrativa ${ }^{25}$, ao invés de aumentar a accountability.

Essas críticas preliminares são importantes ao analisar o PLS 488/2017. Embora seja importante que existam regulações para a produção de projetos de lei que constituam políticas públicas, isso não quer dizer que a simples edição de leis levará a uma maior eficiência na produção legislativa brasileira. Essa eficiência deve ser garantida por outras formas, que utilizem a lei, mas não apostem todas as suas fichas nela.

Isso vale, sobretudo, para as políticas públicas. Considerando-se as determinações sugeridas pelo projeto, vale uma reflexão antes de prosseguir para a avaliação de seu conteúdo, uma espécie de meta-avaliação: o próprio PLS 488/2017 poderia ser pensado à luz dos quesitos de avaliação que propõe, sendo ele mesmo um projeto de lei que constitui políticas públicas? Não se pode esperar que os proponentes do projeto se

21 BOGOSSIAN, Andre. Levando o orçamento a sério como instrumento de controle de políticas públicas. Revista Brasileira de Politicas Públicas, Brasília, v. 5, n. 3, p. 178-198, 2015. p. 185.

22 BRASIL. Constituição da República Federativa do Brasil de 1988. Disponível em < http://www.planalto.gov.br/ccivil_03/constituicao/constituicao.htm>. Acesso em: 25 mar. 2018.

23 BAHIA, Alexandre; NUNES, Dierle. Crise da Democracia Representativa - infidelidade partidária e seu reconhecimento judicial. Revista Brasileira de Estudos Politicos, v. 100, p. 57-84, p. 59-60, 2010.

24 AMARAL, Gilberto Luiz do; OLENIKE, João Elói; STEINBRUCH, Fernando et al. Quantidade de normas editadas no Brasil: 28 anos da Constituição Federal de 1988. São Paulo: Instituto Brasileiro de Planejamento Tributário, 2016. Disponível em: <https:// ibpt.com.br/img/uploads/novelty/estudo/2603/QuantidadeDeNormas201628AnosCF.pdf>. Acesso em: 27 jul. 2018.

25 SODRÉ, Habacuque Wellington. As deficiências da atuação como fator de ativismo: hipertrofia e omissão legislativa. Uma análise da sociologia jurídica sobre o caso brasileiro de ativismo judicial. Direito Público, Porto Alegre, v. 8, n. 43, p. 178-181, jan./ fev. 2012. 
sintam obrigados por uma lei que, ainda, não foi editada (curiosamente, o próprio projeto), mas, ainda assim, a aplicação pode nos ajudar a entender a extensão do próprio PLS 488/2017. A definição de política pública é disputada ${ }^{26}$, e o PLS 488/2017 dá sua própria definição do termo. Faremos, portanto, uma análise da definição do projeto, vendo se ele mesmo cumpriria os requisitos teóricos, e depois expandiremos essa análise. Seguiremos um pequeno roteiro proposto por Secchi para refletir sobre o conceito de política pública, já que, como não há consenso científico, qualquer definição de política pública será arbitrária ${ }^{27}$. As perguntas que parecem nortear as diversas definições são: 1) "Políticas públicas são elaboradas exclusivamente por atores estatais?”; 2) "Políticas públicas também se referem à omissão, ou à negligência?”; 3) "Apenas diretrizes estruturantes (de nível estratégico) são políticas públicas?”28.

O artigo 17-A do PLS 488/2017, em seu $\ 1^{\circ}$, faz uma espécie de glossário, esclarecendo os termos apontados no caput. Assim, política pública está definida no inciso I como "mobilização político-administrativa para articular e alocar recursos e esforços com vistas a solucionar problema coletivo" ${ }^{29}$. É uma definição sucinta, mas é suficiente para avaliar qual a tendência adotada no projeto, e se o projeto pode ser previamente enquadrado. Com relação à $1^{a}$ pergunta, parece-nos que o conceito aqui está restrito ao Estado como ator das políticas reguladas (chamado no projeto de mobilização político-administrativa), já que o objetivo é regular políticas públicas que demandem proposições legislativas, o que vale para o próprio PLS 488/2017. Quanto à $2^{a}$ pergunta, ao dizer que políticas públicas devem fazer alocação de "recursos" e "esforços", parece-nos que a omissão ou negligência não pode ser considerada uma política pública no conceito abordado pelo PLS 488/2017, respondendo, de forma negativa, ao segundo questionamento levantado pelo autor. Além disso, essa questão é de menor importância no debate, já que o projeto regula políticas públicas que demandem projeto de lei, portanto, ação e não omissão ou negligência. Por fim, com relação à $3^{a}$ pergunta, analisando-se, apenas, o conceito de política pública do PLS 488/2017, não parece ser possível aduzir se os propositores pensaram em políticas num nível estratégico ou operacional. Porém, a leitura completa do projeto faz-nos crer que, ao entrar em minúcias e apontar responsabilidades, o projeto não esteja restringindo políticas públicas a apenas um nível de atuação do Estado (micro ou macro). Isso pode apontar que, em relação à normativa proposta pelo PLS 488/2017, qualquer nível estratégico que demande recursos ou esforços dos atores políticos envolvidos pode estar submetido à sua normatização, o que, ainda, não o exclui, em termos conceituais, de ser ele mesmo um projeto de lei que constitua política pública.

Expandindo a reflexão, e acompanhando a sistematização das tipologias feita por Secchi, uma das possíveis classificações de políticas públicas (proposta por Theodore Lowi) é a de políticas constitutivas. Assim, as políticas constitutivas são aquelas que "definem as competências, jurisdições, regras da disputa política e da elaboração de políticas públicas". Além disso, elas podem provocar "conflito entre os entes e os atores diretamente interessados", porque possuem a "capacidade de alterar o equilíbrio de poder existente". Ainda, essas políticas são pouco discutidas, já que "os usuários das políticas públicas e o cidadão comum raramente se interessam por esse tipo de política, já que não tratam de prestação de serviço ou de ações concretas de governo" ${ }^{30}$.

Parece-nos claro que o PLS 488/2017 é, por si mesmo, uma política pública, que tem como objetivo regular a proposição das políticas públicas que tenham como instrumento a proposição legislativa, ou seja, trata-se de uma meta-política. Acompanhando a reflexão de Secchi, parece-nos fundamental que essas meta-políticas sejam, também, avaliadas e acompanhadas, sobretudo porque têm influência direta em todas as

26 SOUZA, Celina. Políticas públicas: uma revisão da literatura. Sociologias, Porto Alegre, ano 8, n. 16, p. 20-45, jul./dez. 2006.

27 SECCHI, Leonardo. Políticas públicas: conceitos, esquemas de análise, casos práticos. São Paulo: Cengage Learning, 2010 , p. 2.

28 SECCHI, Leonardo. Políticas públicas: conceitos, esquemas de análise, casos práticos. São Paulo: Cengage Learning, 2010 , p. 2.

29 BRASIL. Projeto de Lei Complementar do Senado nº 488 de 2017 - Texto final. Acrescenta dispositivos à Lei Complementar $n^{\circ} 95$, de 26 de fevereiro de 1998, com o intuito de estabelecer normas e diretrizes para encaminhamento de proposições legislativas que instituam políticas públicas, propiciando melhor responsabilidade gerencial na Administração Pública. Disponível em: <https:// legis.senado.leg.br/sdleg-getter/documento?dm=7326614\&disposition=inline> Acesso em: 15 maio 2018.

30 SECCHI, Leonardo. Políticas públicas: conceitos, esquemas de análise, casos práticos. São Paulo: Cengage Learning, 2010. p. 18. 
demais políticas e, se mal formuladas, podem dificultar ou a atuação do Poder Executivo ou o controle sobre ela.

Essa reflexão permite que façamos, ao mesmo tempo, uma análise do PLS 488/2017 tanto em termos de conteúdo e aplicação a outros projetos quanto em termos formais, nos próprios termos a que pretende submeter as demais propostas, que é o que faremos em seguida. Porém, como nos submeteremos a uma linha teórica específica das políticas públicas baseadas em evidências comportamentais, faremos antes uma apresentação dessa corrente.

\section{Políticas públicas baseadas em EVIdênCias}

Dentre as possíveis abordagens às políticas públicas, é possível assumir uma perspectiva prescritiva (como deve ser feita a política pública) ou descritiva (como é feita a política pública). A abordagem que enfatiza o uso das evidências (evidence-based policy) é uma abordagem prescritiva, e que pode ser compatibilizada com a compreensão descritiva das políticas em termos de ciclos, que é uma das mais tradicionais do campo de políticas públicas. O modelo dos ciclos de políticas públicas possui cinco passos ou cinco etapas: montagem de agenda, formulação da política, tomada de decisão, implementação da política e avaliação da política.

Na primeira etapa, a montagem de agenda, o problema está sendo reconhecido pelos atores políticos e há diversidade de escolhas e soluções. Na segunda etapa, formulação da política, excluem-se as opções não executáveis e cada um dos atores políticos envolvidos age tentando fazer com que a sua solução favorita do problema seja a escolhida. Na terceira etapa, relativa à tomada de decisão, o governo ou o responsável, efetivamente, escolhe uma das soluções, que será concretizada na quarta etapa, relativa à implementação da política. Nesse momento, a decisão é colocada em ação, usando ferramentas disponíveis à administração pública, que visem alterar distribuição de recursos e serviços na sociedade. A quinta etapa, por fim, é a de avaliação da política, quando tanto atores estatais quanto sociais monitoram os resultados alcançados pela política $^{31}$.

Esse modelo baseado em etapas ajuda a vislumbrar a política em seu aspecto prático, possibilitando, inclusive, que haja critérios específicos para cada uma das fases: aquilo que é necessário saber e fazer na fase de implementação certamente diverge daquilo que se precisa na fase de avaliação, até mesmo em termos de capacidades e agentes. No entanto, como qualquer modelo, essa categorização das políticas em ciclos é uma idealização do processo real no campo de atuação. Na prática, essas fases se "apresentam misturadas" e as "sequências se alternam" 32 .

As evidências científicas em geral podem ser utilizadas em diversas etapas do ciclo de políticas públicas, e de diversas formas. Uma das formas possíveis de conexão entre evidência e política pública consiste em usar as próprias políticas como fonte de evidências. Assim, os atores políticos aprenderiam com o passado e utilizariam políticas anteriores como base para novos desenhos de políticas. As evidências devem vir, portanto, antes da proposição das políticas, por meio de análises sistemáticas dos efeitos de políticas similares. Não se pode recusar a utilidade desse tipo de evidência, e

claro é que a pesquisa em política tem muito a ganhar seguindo uma sequência em que as intervenções sociais são instadas a tentar, tentar e tentar de novo resolver os problemas com os quais a sociedade moderna se confronta. Essa é a raison d'être por trás da atual explosão do interesse nas políticas baseadas em evidências ${ }^{33}$.

31 HOWLET'T, Michael; GIEST, Sarah. The policy-making process. In: ARARAL, Eduardo Araral Jínior et al (Org.). Routledge Handbook of Public Policy. Canada: Routledge, 2013. p. 17-28. p. 17.

32 SECCHI, Leonardo. Políticas públicas: conceitos, esquemas de análise, casos práticos. São Paulo: Cengage Learning, 2010. p. 33.

33 Tradução livre de: "What is clear is that policy research has much to gain by following the sequence whereby social interventions are mounted in trying, trying, and then trying again to tackle the stubborn problems that confront modern society. This is the raison d'etre bebind the current explosion 
Um bom exemplo de evidência proveniente das próprias políticas é o estudo de judicialização das políticas de saúde. Nesse caso, vê-se que o poder judiciário pode interferir na produção de políticas, e busca-se verificar a extensão dessa interferência. Percebe-se que a judicialização "da saúde apresenta uma característica incomum, quando identificado o caráter individualista dos processos litigiosos que englobam pretensões por tratamentos específicos, atingindo o interesse coletivo, ao destinar um recurso não previsto da saúde para contemplar uma demanda específica". Essa percepção localizada deve permitir que os formuladores compreendam onde estão os problemas das políticas de saúde e discutam quem são os atores legítimos no processo decisional de alocação de recursos da área ${ }^{34}$.

Essa abordagem, no entanto, limita-se ao uso de evidências de dentro, provenientes das políticas e dos estudiosos da área. Outra forma de vislumbrar o uso de evidências nas políticas públicas passa pela compreensão de que as evidências devem ser capazes de informar o tomador de decisão, sem limitar a fonte de onde provém essas evidências.

O uso de evidências de fora nas políticas públicas é defendido num movimento acadêmico, que vem se consolidando, de análise de políticas públicas, que busca a "geração e mobilização de conhecimento" com base científica que possa "dar suporte ou influenciar o processo das políticas públicas, especialmente a tomada de decisão e a formulação das políticas", mas também o momento de "implementação" e de "avaliação" 35. A concepção de um movimento é útil para juntar aqueles que estão se esforçando para "reconceber o papel dos governos na sociedade e renegociar aspectos da relação entre indivíduos, coletividades e governos" 36 .

Nota-se, nessa definição, um foco no uso de evidências ou de conhecimento com base científica. É um movimento que busca fazer análises para políticas públicas, fazendo pesquisas que ajudem a formulação, implementação e avaliação das políticas, inserindo as pesquisas nos ciclos das políticas públicas ${ }^{37}$. O movimento de políticas públicas baseadas em evidências é, de alguma forma, uma continuação recente desse esforço $^{38}$.

O próprio movimento em geral de práticas baseadas em evidências surgiu na medicina nos anos 1990, e então se espalhou por diversos campos do saber ${ }^{39}$. No caso das políticas públicas baseadas em evidências, costuma-se dar foco na importância do uso de evidências nos processos de tomada de decisão, buscando diminuir a distância que existe entre a expectativa do criador de política pública e as condições concretas em que as ações serão executadas ${ }^{40}$. Os primeiros estudos que se preocupavam com a tomada de decisão, não apenas na esfera pública, mas também na esfera privada, afirmavam que os tomadores de decisão deveriam "seguir um método sistemático para chegar a decisões lógicas e eficientes" ${ }^{41}$. Assim, o movimento de

of interest in evidence-based policy". PAWSON, Ray. Evidence-based policy: in search of a method. Evaluation, v. 8, n. 2, p. 157-181, 2002. 34 DIAS, Maria Socorro de Araújo et al. Judicialização da saúde pública brasileira. Revista Brasileira de Políticas Públicas, Brasília, v. 6, n. 2, p. 132-145, 2016.

35 Tradução livre de: "Policy analysis — defined as the generation and mobilization of knowledge (with a scientific base) to support or influence public policy process, especially decision-making and policy formulation, but also its implementation and evaluation." FARAH, Marta Ferreira Santos. An analysis of public policies in Brazil: from an unnamed practice to the institutionalization of the" public field". Revista de Administração Pública, v. 50, n. 6, p. 964, 2016.

36 Tradução livre de trechos de: "The rise of policy analysis is usefully construed as a movement. Use of this term implies a deliberate effort on the part of many people to reconceive the role of government in society and renegotiate aspects of the relationships that exist between individuals, collectivities and governments.". MINTROM, Michael, WILLIAMS, Claire. Public policy debate and the rise of policy. In: ARARAL, Eduardo Araral Júnior et al (Org.). Routledge Handbook of Public Policy. Canada: Routledge, 2013. p. 3. 37 FARAH, Marta Ferreira Santos. An analysis of public policies in Brazil: from an unnamed practice to the institutionalization of the" public field". Revista de Administração Pública, v. 50, n. 6, p. 964-973, 2016.

38 HOWLETT, Michael. Policy analytical capacity and evidence-based policy-making: lessons from Canada. Canadian public administration, v. 52, n. 2, p. 154, 2009.

39 TRINDER, Liz. Introduction: the context of evidence-based practice. In: TRINDER, Liz; REYNOLDS, Shirley (Org.). Evidence-based practice: a critical appraisal. Oxford: Blackwell, 2003. p. 2.

40 HOWLETT, Michael. Policy analytical capacity and evidence-based policy-making: Lessons from Canada. Canadian public administration, v. 52, n. 2, p. 154, 2009.

41 Tradução livre de trecho de: "Many early studies of policy-making in companies, governments, and organizations conducted largely by students 
política pública baseada em evidências (PPBE) reconhece a responsabilidade do tomador de decisões de usar evidências de forma conscienciosa para desenhar, gerir e reformar sistemas de suporte a comunidades de uma forma previsivelmente capaz de trazer benefícios. Em teoria, PPBE significa que cientistas produzem evidências que decisores públicos podem usar em suas decisões ${ }^{42}$.

Antes de prosseguirmos para a apresentação do movimento de análise de políticas públicas ou de políticas públicas baseadas em evidências no Brasil, é importante, primeiramente, destacar as críticas que podem ser feitas ao uso de evidências nas políticas públicas. Uma delas diz respeito à capacidade de o tomador de decisão público acessar, criticar e avaliar as evidências provenientes de diversas áreas do saber. Não se pode presumir essa capacidade e uma dificuldade importante do movimento é a de como fornecer "aos trabalhadores do setor público" as "ferramentas necessárias para avaliar a qualidade da evidência" 43 . Isso demanda que o ator político seja capaz de acessar, de alguma forma, essas evidências, seja sabendo qual a área pode lhe ser conveniente, seja sendo capaz de acessar os pesquisadores de uma determinada área ou, ainda, ter acesso a periódicos científicos de qualidade, se souber como e o que procurar. Essa crítica ainda ressalva a importância de se considerar o contexto político e, inclusive, educacional no qual o criador de política pública está inserido. Um estudo no Canadá demonstrou a disparidade de capacidade analítica e política de atores em diversas esferas político-administrativas, assim como dificuldade em utilizar evidências nos processos de decisão ${ }^{44}$. E se isso vale para países desenvolvidos, a questão é provavelmente ainda mais complexa em países em desenvolvimento, como é o caso do Brasil.

Há algumas formas de mitigar essa dificuldade de acesso às evidências disponíveis na literatura. Uma delas é cobrando dos tomadores de decisão transparência e accountability no processo de produção de políticas públicas baseadas em evidências. A transparência permite ao público em geral que acompanhe o processo de utilização das evidências, diminuindo o risco de haver "erros simples, desenhos de pesquisa insuficientes e enviesamento completo de resultados e conclusões" 45 . Para tornar a PPBE mais transparente, sugere-se tornar "os dados não tratados disponíveis", o "instrumento de coleta de dados disponível", permitir acesso aos "metadados"; tornar as "assunções analíticas explícitas"; fazer "escolhas analíticas e testá-las explicitamente"; tornar a "perspectiva teórica explícita"; deixar clara a relação com "pesquisas passadas" e declarar "interesses financeiros" e de outros tipos ${ }^{46}$.

No processo de accountability, a questão é abrir espaço não apenas para que vejam os dados usados, mas para que possam argui-lo, questioná-lo. O termo accountability incorpora "conceitos correlatos como 'discussão', 'revisão', 'avaliação' ou 'consulta”'. Mas, além de abrir a conversa, demanda do criador de políticas que ele engaje "outras pessoas significativas" nesse debate. Aqueles para os quais a PPBE deve ser accountable são "aqueles afetados pelas políticas"; "aqueles que possuem diferentes estruturas conceituais"; aqueles que

of public and business administration, for example, argued that decision-makers attempt to follow a systematic method for arriving at logical, efficient decisions." HOWLETT, Michael; GIEST, Sarah. The policy-making process. In: ARARAL, Eduardo Araral Jr. et al (Orgs.). Routledge Handbook of Public Policy. Simultaneously published in the USA and Canada: Routledge, 2013, p. 20.

42 Tradução livre de: "Evidence-based policy (EBP) acknowledges the responsibility of decision makers for the conscientious use of evidence to design, manage and reform systems of support for communities in a manner that predictably yield outcomes of benefit. In theory, EBP means-scientists produce evidence, which policy decision makers can use for decisions." REDDY, K. Srikanth; SAHAY, Seema. Voices of decision makers on evidencebased policy: a case of evolving TB/HIV co-infection policy in India. AIDS care, v. 28, n. 3, p. 397, 2016, p.

43 Tradução livre de trechos de: "Another area of research around EBP aims to provide public sector workers with the tools needed to assess the quality of evidence." ARGYROUS, George. Evidence based policy: principles of transparency and accountability. Australian Journal of Public Administration, v. 71, n. 4, p. 457, 2012.

44 HOWLETT, Michael. Policy analytical capacity and evidence-based policy-making: Lessons from Canada. Canadian public administration, v. 52, n. 2, p. 153-175, 2009.

45 Tradução livre de: "In other words, transparency is a safeguard against simple errors, poor research design, and outright biasing of results and conclusions."

46 Tradução livre de: "1. Make raw data available; 2. Make the data collection instrument available; 3. Make metadata available; 4. Make analytical assumptions explicit; 5. Make analytical choices and their testing explicit; 6. Make theoretical perspectives explicit; 7. Make the relationship with past research explicit; 8. Declare financial and other interests.". ARGYROUS, George. Evidence based policy: principles of transparency and accountability. Australian Journal of Public Administration, v. 71, n. 4, p. 457-468, 2012, p. 459. 
possuem "expertise" e "leitores inteligentes ou potenciais usuários das evidências" ${ }^{47}$.

Essa estratégia de transparência e accountability parece mais adequada, inicialmente, para a perspectiva do uso de evidências geradas pelas próprias políticas públicas. No entanto, transparência e accountability também devem ser requeridas na escolha e na aplicação de evidências provenientes de outras áreas e pesquisadores, diminuindo vieses de seleção nas evidências escolhidas, além de evitar pesquisas pouco relevantes ou com falhas metodológicas. Além disso, essa estratégia pode conferir ao criador de política a responsabilidade de abrir diálogo com aqueles que podem auxiliá-lo, por deter conhecimentos específicos, atribuindo também aos pesquisadores capazes a responsabilidade de se engajar com as questões políticas concretas dos contextos em que estão inseridos.

Outra crítica que merece menção questiona o próprio papel das políticas públicas e do ator político, e pode ser colocada de forma geral como uma crítica à tecnocracia. O que é argumentado é que usar evidências já constitui um processo natural na produção de políticas públicas e o que está em discussão, na verdade, são quais evidências serão válidas, não o seu uso. Assim, os agentes estariam depositando na ciência uma fé que não é corroborada nem pela ciência nem pelo público em geral. Essa fé capacita os atores a mascarar suas decisões políticas em evidências racionais, colocando-se acima das críticas sob o manto da racionalidade prática (escolhendo aquilo que funciona). Essa perspectiva ignoraria a importância da interpretação dessas evidências e o caráter inter-relacional de uma decisão pública. Em última instância, as evidências seriam usadas, apenas, para reforçar uma decisão já tomada, sobretudo se contra-majoritária, dando poder aos técnicos ou aos que utilizam desse discurso tecnocrata ${ }^{48}$.

De fato, o movimento de políticas públicas baseadas em evidências considera dados advindos de diversas áreas do conhecimento e outros órgãos que se proponham a sistematizar e compreender a realidade por meio de métodos confiáveis e verificáveis, e está clamando por um uso de evidências especificamente controladas. Isso, no entanto, não deveria ser tomado como uma crítica ao movimento, mas como um alerta aos cidadãos para que façam um controle democrático e acessem os métodos decisórios e as justificativas dos tomadores de decisão. $\mathrm{O}$ uso das evidências não é a fonte do discurso tecnocrata, mas apenas uma ferramenta que pode ser assumida por políticos, e que pode ser usada para sustentar decisões diversas e alcançar objetivos igualmente diversos. O combate à tecnocracia se faz com conhecimento do público em geral, não com o desencorajamento do uso de evidências.

\subsection{O movimento de análise de políticas públicas e de políticas públicas baseadas em evidências no Brasil e o PLS 488/2017}

No Brasil, o interesse pela análise de políticas públicas pode ser considerado um movimento ocorrido pós-1930, com a tomada do poder pelo Presidente Getúlio Vargas ${ }^{49}$. No entanto, da perspectiva acadêmica, a literatura específica sobre políticas públicas em geral criada no Brasil começa a se consolidar, apenas, nos anos 2000. Quanto ao método adequado para a análise das políticas públicas, não havia, ao menos até 2016, nenhum livro publicado originalmente no país ${ }^{50}$.

47 Tradução livre de: 'In this way, accountability incorporates related concepts such as 'discussion', 'review', 'evaluation', or 'consultation' [...]But is also demands more of the policy-maker in terms of the extent to which they need to engage the views of 'significant others', [...] 1. Those affected by policy; 2 . Those with different conceptual frameworks; 3 . People with technical expertise; 4. Intelligent readers or potential users of the evidence". ARGYROUS, George. Evidence based policy: principles of transparency and accountability. Australian Journal of Public Administration, v. 71, n. 4, p. 463-464, 2012.

48 BLACK, Nick. Evidence based policy: proceed with care. British Medical Journal (BMJ), v. 323, n. 7307, p. 275, 2001; CLARENCE, Emma. Technocracy reinvented: the new evidence based policy movement. Public Policy and Administration, v. 17, n. 3 , p. $1-11$, July 2002.

49 FARAH, Marta Ferreira Santos. An analysis of public policies in Brazil: from an unnamed practice to the institutionalization of the" public field". Revista de Administração Pública, v. 50, n. 6, p. 965, 2016; SECCHI, Leonardo. Policy analysis in Brazil: a comparison of rationalist and argumentative approaches. Journal of Comparative Policy Analysis: research and practice, v. 18, n. 1, p. 89, 2016.

50 SECCHI, Leonardo. Policy Analysis in Brazil: a Comparison of Rationalist and Argumentative Approaches. Journal of Compara- 
Esse cenário se mantém e é ainda mais difícil encontrar material escrito em Língua Portuguesa sobre políticas públicas baseadas em evidências. Uma busca rápida no Portal Capes ${ }^{51} \mathrm{com}$ a expressão "políticas públicas baseadas em evidências" e afins ${ }^{52}$ retornou apenas quatro resultados. O que não quer dizer, é claro, que não se usam evidências nas abordagens acadêmicas às políticas públicas no Brasil, ou que pesquisadores brasileiros não têm produzido trabalhos nessa área até mesmo em outros idiomas, mas dá uma ideia do quão recente é essa abordagem por aqui.

Uma das áreas das políticas públicas que está mais avançada em termos de uso de evidências no Brasil e no mundo é a área da saúde pública. Talvez porque o movimento baseado em evidências em geral tenha surgido na medicina, ou porque, no contexto da própria área da saúde, a

ciência básica na qual as decisões tomadas baseadas em evidências estão sediadas é a epidemiologia, e a saúde pública está numa posição ideal para liderar o trabalho da tomada de decisão baseada em evidências porque é uma das poucas disciplinas nas quais a epidemiologia é a ciência basilar ${ }^{53}$.

Um trabalho interessante, por exemplo, busca compreender o uso de evidências científicas para o controle do cigarro no Brasil, defendendo uma diminuição da distância (gap) entre a ciência e a saúde pública. Demonstra que, dentre as lições extraídas do controle de cigarro, há a necessidade de ações coordenadas de diferentes atores e grupos influenciando os objetivos da saúde pública brasileira e de que a pesquisa científica deve auxiliar os criadores de políticas com evidências de suas respectivas áreas ${ }^{54}$.

As pesquisas na área já começam, inclusive, a fazer críticas à qualidade dos dados usados pelo governo. Um dos problemas diz respeito às conquistas e às dificuldades do SUS, o Sistema Único de Saúde. Assim, se

o objetivo é o de gerar informação relevante para iluminar a tomada de decisão referente às políticas públicas em saúde, devemos nos dedicar de forma sistemática a avaliar, pelo método científico, os resultados assistenciais do SUS. Entretanto, passados 25 anos da implantação do SUS, temos poucas evidências científicas, especialmente que representem o país continental que somos, quais são os resultados assistenciais finalísticos do SUS ${ }^{55}$.

Percebe-se com isso que o debate sobre as políticas públicas baseadas em evidências, ainda que incipiente no Brasil com relação aos aspectos teóricos e metodológicos, já foi iniciado por alguns estudiosos e criadores de políticas públicas, especialmente da área da saúde.

Tanto o guia de análise ex ante das políticas públicas e o PLS 488/2017 são, também, outras possíveis aberturas, no cenário brasileiro, para a importância do uso de evidências nas políticas públicas. O guia expressa a importância das evidências em dois momentos. O primeiro se refere à identificação dos problemas, sendo essencial "a apresentação de dados quantitativos e estudos qualitativos para evidenciar a natureza e a dimensão do problema identificado e, quando possível, a sua evolução ao longo do tempo" ${ }^{56}$. O segundo,

tive Policy Analysis: Research and Practice, v. 18, n. 1, p. 91, 2016.

51 "O Portal de Periódicos, da Coordenação de Aperfeiçoamento de Pessoal de Nível Superior (Capes), é uma biblioteca virtual que reúne e disponibiliza a instituições de ensino e pesquisa no Brasil o melhor da produção científica internacional. Ele conta com um acervo de mais de 38 mil títulos com texto completo, 134 bases referenciais, 11 bases dedicadas exclusivamente a patentes, além de livros, enciclopédias e obras de referência, normas técnicas, estatísticas e conteúdo audiovisual.” Disponível em: < http:// www-periodicos-capes-gov-br.ez27.periodicos.capes.gov.br/index.php?option $=$ com_pcontent\&view $=$ pcontent\&alias $=$ missaoobjetivos\&Itemid=102>. Acesso em: 10 abril 2018.

52 Foram utilizadas também: "política pública baseada em evidência"; "políticas públicas baseadas em evidência"; "política pública fundamentada em evidência"; "políticas públicas fundamentadas em evidências"; "política pública fundamentada em evidências". 53 Tradução livre de: "The basic science on which evidence-based decision-making is based is epidemiology, and public health is ideally positioned to lead work in evidence-based decision-making because it is one of the few disciplines in which epidemiology is one of the basic sciences." GRAY, J. A. Muir. Evidence-Based Public Health. In: TRINDER, Liz; REYNOLDS, Shirley (Orgs.). Evidence-based practice: A critical appraisal. Oxford: Blackwell, p. 1-16, 2003, p. 105.

54 COSTA E SILVA, Vera Luiza et al. Bridging the gap between science and public health: taking advantage of tobacco control experience in Brazil to inform policies to counter risk factors for non-communicable diseases. Addiction, v. 108, n. 8, p. 1360-1366, 2013. 55 OLIVEIRA, Jussiely Cunha; BARRETO-FILHO, José Augusto. Políticas Públicas em Saúde Embasadas em Ciência "Made In Brazil": um desafio para os Arquivos Brasileiros de Cardiologia. Arq. Bras. Cardiol., v. 105, n. 3, p. 211, 2015. p.

56 BRASIL. Casa Civil da Presidência da República. Avaliação de políticas públicas: guia prático de análise ex ante. Brasília: Ipea, 2018. 
à fundamentação da escolha ou tomada de decisão, quando se devem expor

todas as informações que auxiliaram o processo de construção da política e justificam a escolha da intervenção conforme apresentada. Para compor esta etapa, sempre que possível, deve-se apresentar uma revisão de literatura indicando que o modelo lógico proposto tem o potencial de alcançar os impactos esperados. Outras fontes de informação utilizadas na construção da política - como grupos focais, entrevistas com especialistas, exemplos de outras experiências similares nacionais ou internacionais devem ser especificadas quando pertinentes. ${ }^{57}$.

O PLS 488/2017, por sua vez, trata de outro espaço interessante para o uso de evidências. No art. 17-A, o projeto estabelece que os projetos de lei que instituam política pública deverão ser "acompanhados de avaliação prévia de impacto legislativo, com o intuito de garantir a economicidade, a eficácia, a eficiência e a efetividade das ações públicas." ${ }^{58}$. Numa Análise de Impacto Legislativo (AIL) devem constar: qual o problema que se quer resolver; quais os objetivos da proposição legislativa; quais as opções disponíveis para alcançar esses objetivos; qual o arcabouço jurídico que importa ao tema; quais os possíveis impactos econômicos e sociais que podem ser gerados caso a proposição seja aprovada ${ }^{59}$.

Mas AILs não devem ser feitas em qualquer espécie de proposição legislativa. Merecem avaliações de impacto legislativo as proposições legislativas que "imponham ou reduzam custos à iniciativa privada, ao terceiro setor ou ao próprio setor público", dependendo do valor, além das "situações em que ocorrerá uma grande redistribuição de custos e benefícios entre grupos da sociedade" ${ }^{60}$.

Assim, fica claro que as proposições que instituam políticas públicas atingem os critérios auferidos por MENEGUIN. Em termos de ciclo das políticas públicas, parece-nos adequado dizer que essa AIL deve acontecer como resultado da tomada de decisão (terceira etapa do ciclo de políticas públicas), quando as opções já foram cogitadas e decidiu-se por um curso de ação, e que é também a etapa do ciclo de política pública em que o movimento de política pública baseada em evidências costuma focar. A proposição de um projeto de lei é uma resposta a uma decisão, e pode ser considerada parte da implementação da política, já que começa a demandar esforços, articulações, enfim, alguma espécie de ação por parte do agente político.

A diferença entre uma AIL e uma avaliação de política pública num sentido mais amplo não é óbvia.

Após detida análise dos conceitos e exemplos encontrados na literatura sobre os dois temas, pode-se depreender que o entendimento vigente diferencia o que seja avaliação de políticas públicas, avaliação de programas de governo e avaliação de impacto legislativo. A percepção que se tem é que: a) os programas públicos, dada sua complexidade, não necessitam de previsão normativa para sua legitimação; b) a análise de políticas públicas ocorre somente sobre políticas sociais; e c) a análise de impacto legislativo incide sobre o processo de elaboração normativa stricto senso $\mathrm{s}^{61}$.

Como a proposição de políticas públicas pressupõe algum arcabouço legal que a permita e regule,

ao se considerar os objetivos, a metodologia e os princípios aplicados, pode-se afirmar que avaliação de políticas públicas e avaliação de impacto legislativo partem dos mesmos pressupostos de ação e

v. 1. p. 58 .

57 BRASIL. Casa Civil da Presidência da República. Avaliação de políticas públicas: guia prático de análise ex ante. Brasília: Ipea, 2018 v. 1. p. 58 .

58 BRASIL. Projeto de Lei Complementar do Senado n 488 de 2017 - Texto final. Acrescenta dispositivos à Lei Complementar $n^{\circ} 95$, de 26 de fevereiro de 1998, com o intuito de estabelecer normas e diretrizes para encaminhamento de proposições legislativas que instituam políticas públicas, propiciando melhor responsabilidade gerencial na Administração Pública. Disponível em: <https:// legis.senado.leg.br/sdleg-getter/documento?dm=7326614\&disposition=inline >. Acesso em: 15 maio 2018.

59 MENEGUIN, Fernando B. Avaliação de impacto legislativo no Brasil. Brasília: Senado Federal, Consultoria Legislativa, Textos para Discussão 70. 2010. p. 10-11. Disponível em: < https://www12.senado.leg.br/publicacoes/estudos-legislativos/tipos-de-estudos/ textos-para-discussao/td-70-avaliacao-de-impacto-legislativo-no-brasil>. Acesso em: 25 abr. 2018.

60 MENEGUIN, Fernando B. Avaliação de impacto legislativo no Brasil. Brasília: Senado Federal, Consultoria Legislativa, Textos para Discussão 70, 2010. P.10 Disponível em: <https://www12.senado.leg.br/publicacoes/estudos-legislativos/tipos-de-estudos/ textos-para-discussao/td-70-avaliacao-de-impacto-legislativo-no-brasil>. Acesso em: 25 abril 2018.

61 ANDRADE, Aparecida de Moura; SANTANA, Héctor Valverde. Avaliação de políticas públicas versus avaliação de impacto legislativo: uma visão dicotômica de um fenômeno singular. Revista Brasileira de Políticas Públicas, Brasília, v. 7, n. 3, p. $796,2017$. 
compartilham dos mesmos resultados da avaliação de impacto legislativo: avaliar a eficiência, eficácia e efetividade da norma que institui uma política pública, seja ela distributiva, redistributiva ou regulatória ${ }^{62}$.

Embora o texto do PLS 488/2017 recomende a todos os projetos de lei que deem origem a políticas públicas que façam uma Análise do Impacto Legislativo (AIL), ainda assim não tivemos acesso a nenhuma AIL feita para o projeto em si, já que não há nada nesse sentido anexado ao projeto ou disponibilizado em documentos durante a tramitação no Senado ou na Câmara. Dentre as razões para o não cumprimento das exigências, como já foi especulado na seção 1 do presente artigo, pode-se levantar a de que os propositores do projeto não consideraram-no uma proposição de política pública, ou, ainda, se dever à ausência de um texto anterior que os "obrigue".

Tendo mapeado a possibilidade do uso de políticas públicas baseados em evidências em geral, e sua ainda incipiente aparição em território nacional, cabe agora passar ao tema mais específico das evidências comportamentais nas políticas públicas.

\section{As POLÍTICAS PÚBLICAS E AS EVIDÊNCIAS COMPORTAMENTAIS}

O movimento de políticas públicas baseadas em evidências costuma abarcar estudos que buscam entregar evidências que ajudem os criadores de políticas públicas no processo de tomada de decisão. Uma das áreas mais fortes dessa corrente, atualmente, é a que busca utilizar evidências comportamentais para propor alterações em políticas públicas e em processos de decisão privados, os chamados nudges (pequenos empurrões). Um nudge é um aspecto da "arquitetura de escolha" que visa alterar o comportamento das pessoas de "forma previsível, sem proibir ou alterar significativamente os incentivos econômicos". Assim, um nudge deve ser uma intervenção não explícita, não mandatária e que possa ser recusada pelo público-alvo ${ }^{63}$.

Um nudge é um “empurrãozinho" planejado para influir, positivamente, nas escolhas das pessoas, não as alterando, mas facilitando a escolha considerada melhor. Esses nudges foram propostos no contexto de um "paternalismo libertário", expressão, de alguma forma irônica, cunhada por THALER e SUNSTEIN. Esse paternalismo seria uma versão leve do paternalismo, já que, ao invés de bloquear, cercear, limitar ou alterar significativamente as escolhas das pessoas, o objetivo dos nudges é levar as pessoas a fazerem escolhas melhores, sem com isso decidir por elas ${ }^{64}$.

Essa influência no comportamento por meio dos nudges pode acontecer com base em mecanismos inconscientes; corrigindo incompreensões sobre as normas sociais; alterando o perfil de escolhas ou a forma como as escolhas são apresentadas; mudando a regra padrão (aquela que não demanda esforço do indivíduo), obrigando-o a escolher ativamente uma opção mais custosa ou menos saudável, por exemplo; ou criando incentivos financeiros para que as pessoas façam escolhas melhores, sem criar prejuízos caso elas não as façam ${ }^{65}$.

Os nudges parecem ter ampla aceitação por parte dos cidadãos de diversas nações, tais como Austrália, Canadá, China, Rússia e Brasil ${ }^{66}$. Eles são um tipo de política comportamental (behavioral policy), conceituada

62 ANDRADE, Aparecida de Moura; SANTANA, Héctor Valverde. Avaliação de políticas públicas versus avaliação de impacto legislativo: uma visão dicotômica de um fenômeno singular. Revista Brasileira de Políticas Públicas, Brasília, v. 7, n. 3, p. $796,2017$.

63 Tradução livre de trechos de: "A nudge, as we will use the term, is any aspect of the choice architecture that alters people's behavior in a predictable way without forbidding any options or significantly changing their economic incentives. To count as a mere nudge, the intervention must be easy and cheap to avoid. Nudges are not mandates." THALER, Richard H.; SUNSTEIN, Cass R. Nudge: improving decisions about health, wealth, and happiness. New Haven: Yale University Press, 2008. p. 6.

64 THALER, Richard H.; SUNSTEIN, Cass R. Nudge: improving decisions about health, wealth, and happiness. New Haven: Yale University Press, 2008. p. 5.

65 BONELL, Chris et al. One nudge forward, two steps back. British Medical Journal (BMJ), v. 342, n. jan. 25, p. d401, 2011.

66 SUNSTEIN, Cass R.; REISCH, Lucia A.; RAUBER, Julius. A worldwide consensus on nudging? not quite, but almost. Regulation \& Governance, v. 12, n. 1, p. 3-22, 2018. 
como "intervenções no ambiente de escolha que tem por objetivo afetar o comportamento sem incentivo ou coerção" ${ }^{67}$. Os nudges são uma das formas possíveis de intervenção, mas há outras.

Outra forma importante de política comportamental é a abordagem de boost (impulso). Se nos nudges há uma decisão externa em modificar o comportamento, ainda que de forma suave, nos boosts a ideia é ajudar as pessoas a tomarem decisões mais acertadas levando em conta suas limitações. A abordagem de boosts "admite um tomador de decisão cujas competências podem ser melhoradas", no sentido de melhorar o "repertório de habilidades e ferramentas decisionais e/ou reestruturando o ambiente para que essas habilidades existentes e ferramentas possam ser utilizadas de forma mais efetiva" ${ }^{68}$. Assim, os boosts diferem dos nudges por levarem em conta, também, o melhor da capacidade decisional do público-alvo, e não apenas a alteração do comportamento.

Uma das críticas que podem ser feitas aos nudges ou às políticas comportamentais como um todo diz respeito ao uso de evidências laboratoriais ou de estudos controlados em políticas públicas. Ao transferir as conclusões advindas de uma experiência controlada para outra no mundo real, outras variáveis podem alterar o resultado. Os dados que demonstram os efeitos comportamentais derivados de uma mudança no ambiente de escolha costumam ser extraídos de ambientes diversos daqueles em que serão efetivamente aplicados pelos criadores de políticas públicas, mesmo sendo experimentos de campo ${ }^{69}$. O uso de evidências deve ser sempre acompanhado de prudência nas generalizações e de compreensão dos limites metodológicos dos estudos.

No caso das evidências comportamentais em nudges, há três mecanismos diversos que podem estar atuando. As alterações comportamentais podem estar acontecendo porque os sujeitos preferem não fazer esforço cognitivo, limitando sua decisão à opção menos cognitivamente dispendiosa quando se modifica a escolha padrão disponível ${ }^{70}$. Essa tentativa de evitar a fadiga cognitiva está relacionada ao viés de status quo, que implica dizer que tendemos à inércia, sobretudo pela falta de atenção ou de interesse ao que está sendo apresentado (algo como uma "heurística do 'tanto faz"). Assim, essa tendência é facilmente explorável, já que as pessoas podem, sobretudo, pagar por algo como resultado dessa inércia, preferindo a escolha-padrão a ativamente escolher algo com menos custos $^{71}$.

Outro mecanismo que pode estar operando é da aversão à perda. Quando comparados os ganhos de uma escolha com as perdas de outras, as pessoas tendem a dar maior peso para as perdas, ainda que elas sejam relativamente equivalentes aos ganhos da escolha alternativa ${ }^{72}$. Como os indivíduos tendem a evitar as perdas, quando se muda a escolha-padrão pode ser que se mude também a perspectiva do sujeito com relação à perda e ao ganho de determinada escolha ${ }^{73}$.

O terceiro mecanismo que pode explicar o que ocorre quando uma política comportamental funciona é o efeito da recomendação. Nesse caso, a escolha-padrão pode servir como um sinal de que aquele que formulou o ambiente de escolha está recomendando que se faça a escolha dada como default. Se aquele que

67 Tradução livre de: "Behavioural policies are interventions in the choice environment that aim at affecting behaviour without incentive change or coercion.” GRÜNE-YANOFF, Till. Why behavioural policy needs mechanistic evidence. Economics \& Philosophy, v. 32, n. 3, p. 463-483, 2016, p. 463.

68 Tradução livre de trechos de: "The boost approach, in contrast, assumes a decision maker whose competences can be improved by enriching his or her repertoire of skills and decision tools and/or by restructuring the environment such that existing skills and tools can be more effectively applied”. GRÜNE-YANOFF, Till; HERTWIG, Ralph. Nudge versus boost: How coherent are policy and theory? Minds and Machines, v. 26, n. 1-2, p. 149-183, 2016.

69 GRÜNE-YANOFF, Till. Why behavioural policy needs mechanistic evidence. Economics \& Pbilosophy, v. 32, n. 3, p. 466, 2016.

70 GRÜNE-YANOFF, Till. Why behavioural policy needs mechanistic evidence. Economics \& Philosophy, v. 32, n. 3, p. 467, 2016.

71 THALER, Richard H.; SUNSTEIN, Cass R. Nudge: improving decisions about health, wealth, and happiness. New Haven: Yale University Press, 2008. p. 35.

72 KAHNEMAN, Daniel. Rápido e devagar: duas formas de pensar. Tradução Cássio de Arantes Leite. Rio de Janeiro: Objetiva, 2012. p. 351.

73 GRÜNE-YANOFF, Till. Why behavioural policy needs mechanistic evidence. Economics \& Philosophy, v. 32, n. 3, p. 468, 2016. 
escolhe confia nos formuladores da política, tende a confiar na escolha-padrão ${ }^{74}$.

Não é suficiente que a política comportamental apenas funcione. É preciso entender o mecanismo que faz com que a mudança de comportamento funcione no ambiente experimental, para que, assim, essa evidência possa ser carregada para outras políticas públicas. Sem essa informação, não se pode alegar a efetividade da política, sua robustez ou persistência, ou ainda se ela possui mecanismos positivos de aumento do bem-estar ${ }^{75}$. Todo esse debate demonstra como o uso de evidências comportamentais deve ser mais amplo e como é importante avaliar os dados que estão sendo utilizados.

A proposição de políticas públicas baseadas em evidências não precisa, porém, estar restrita ao uso de nudges. Num sentido mais amplo, as ciências comportamentais devem ser inseridas em diversas outras etapas dos ciclos de políticas públicas, levando em conta não apenas o objetivo esperado, mas também o público-alvo e mesmo o próprio tomador de decisão, melhorando a qualidade das políticas públicas propostas.

Faremos a seguir uma análise mais detalhada das possibilidades de uso de evidências comportamentais no Brasil, à luz do PLS 488/2017.

\subsection{O uso de evidências comportamentais nas políticas públicas no Brasil à luz do PLS 488/2017}

Embora as políticas públicas devam ser baseadas em evidências diferentes, que interfiram no problema público a ser resolvido, as evidências comportamentais, por sua vez, são virtualmente de interesse de qualquer formulador de política pública. A razão para tal é que, em última instância, um dos riscos de praticamente qualquer política é o de interferir de forma não prevista na situação social, afetiva e cognitiva do público-alvo. Além disso, todo tomador de decisão deve estar ciente das razões pelas quais escolheu uma evidência como relevante e deve estar preparado para negociar, explicar e convencer outros atores da força, qualidade e abrangência das evidências usadas.

As ciências comportamentais podem ajudar a alcançar determinado objetivo, e, nesse caso, os nudges podem ser considerados, assim como os boosts ou outras estratégias que usem evidências comportamentais, quando é preciso tomar uma decisão quanto a qual caminho seguir. Eles podem aumentar a efetividade da política pública, compreendida no PLS 488/2017 como o "alcance dos resultados pretendidos, a médio e longo prazo" 76 .

Assim, o PLS 488/2017 abre um espaço importante para que as ciências comportamentais sejam utilizadas para a produção de políticas públicas no Brasil. Essa abertura é detectável em alguns momentos do projeto. No artigo 17-B, inciso IV, afirma-se que os projetos de lei deverão explicitar o "o grau de focalização ou universalização das políticas públicas, considerando as necessidades do público-alvo e os recursos disponíveis" ${ }^{77}$. Essas necessidades devem ser matizadas pelas evidências nas ciências comportamentais, sobretudo tendo em vista a incompletude de nossa consciência de nossas próprias necessidades.

Os nudges são mecanismos que visam "auxiliar" o público-alvo em escolhas determinadas, "facilitando"

74 GRÜNE-YANOFF, Till. Why behavioural policy needs mechanistic evidence. Economics \& Pbilosophy, v. 32, n. 3, p. 469, 2016.

75 GRÜNE-YANOFF, Till. Why behavioural policy needs mechanistic evidence. Economics \& Philosophy, v. 32, n. 3, p. 463-483. 2016.

76 BRASIL. Projeto de Lei Complementar do Senado $n^{\circ} 488$ de 2017 - Texto final. Acrescenta dispositivos à Lei Complementar $\mathrm{n}^{\circ} 95$, de 26 de fevereiro de 1998, com o intuito de estabelecer normas e diretrizes para encaminhamento de proposições legislativas que instituam políticas públicas, propiciando melhor responsabilidade gerencial na Administração Pública. Disponível em: <https:// legis.senado.leg.br/sdleg-getter/documento?dm=7326614\&disposition=inline $>$. Acesso em: 15 maio 2018.

77 BRASIL. Projeto de Lei Complementar do Senado n 488 de 2017 - Texto final. Acrescenta dispositivos à Lei Complementar no 95 , de 26 de fevereiro de 1998, com o intuito de estabelecer normas e diretrizes para encaminhamento de proposições legislativas que instituam políticas públicas, propiciando melhor responsabilidade gerencial na Administração Pública. Disponível em: <https:// legis.senado.leg.br/sdleg-getter/documento?dm=7326614\&disposition=inline > Acesso em: 15 maio 2018. 
a escolha melhor para o longo prazo, mas nem sempre prazerosa no curto prazo. Um exemplo clássico é a mudança na disposição de comidas mais saudáveis em supermercados. Num estudo nos Estados Unidos, mudar a posição de um lanche mais saudável fez com que ele fosse escolhido mais vezes ${ }^{78}$. Em resposta, uma série de estudos tentou averiguar se a mudança da disposição dos produtos poderia levar a mudanças nas escolhas, sem limitar as possibilidades do consumidor. Outras áreas em que há estudos promissores, embora modestos, de nudges, são: transporte, com nudges que encorajam o uso de meios sustentáveis de transporte no Reino Unido; e energia, ao levar a uma diminuição do consumo por meio de pequenas mudanças nas informações disponíveis nas contas de luz $z^{79}$.

Outra sugestão, nesse caso dentro do contexto brasileiro, é a de aproveitar os nudges como forma de combate à corrupção pública, por meio da "utilização de lembretes morais e pela manipulação das normas sociais descritivas". Isso já foi feito em experimentos sociais, nos quais o experimentador lembrava antes aos participantes de regras morais aceitas por eles; e na Índia, ao desenvolver uma cédula correspondente a "zero rúpia”, que indicaria a não aceitação de suborno ${ }^{80}$.

De fato, um exemplo tem sido dado pela Prefeitura do Rio de Janeiro, por meio da recente criação da "Nudge.Rio", uma "célula dentro da estrutura do Instituto Fundação João Goulart" que tem por objetivo "disseminar o conceito de Ciência Comportamental Aplicada nos órgãos da Prefeitura da Cidade do Rio de Janeiro", tendo como foco os nudges ${ }^{81}$.

No caso das necessidades do público-alvo, é importante refletir, portanto, se essas necessidades serão sempre as que puderem ser declaradas pelos cidadãos, sendo escolhas conscientes, ou se é possível considerar que há necessidades que não estão no foco do cidadão no curto prazo, mas que podem beneficiá-lo no longo prazo. Esse é o grande dilema do paternalismo libertário, e deve ser encarado quando se fala em políticas públicas que busquem satisfazer necessidades dos cidadãos.

Assim, o PLS 488/2017 pode ser um bom estímulo a mais núcleos de inovação pública no Brasil, além do estudo das experiências com evidências comportamentais feitas em outros países, ao enfocar a importância do uso de evidências e a explicitação das necessidades a que as políticas públicas pretendem atender.

As ciências comportamentais são ainda mais relevantes para aquele que está decidindo sobre como as políticas públicas deverão ser formuladas, que é o caso do PLS 488/2017. Como já afirmamos, não tivemos acesso a nenhuma AIL do PLS 488/2017. Assim, não podemos, portanto, ter certeza de quais problemas o projeto está tentando resolver, se é uma resposta a alguma demanda específica de algum grupo organizado ou estrutura governamental, se foi feito um estudo de impacto e quais os objetivos mensuráveis que essa política pretende alcançar. Resta-nos, portanto, especular sobre os problemas a serem enfrentados por essa proposição, tendo em vista a estrutura e o conteúdo dos artigos.

Além disso, ao fazer uma avaliação do PLS 488/2017 como um projeto que institui uma política pública, aproveitaremos para demonstrar como o uso de evidências comportamentais pode funcionar na proposição de políticas públicas no Brasil. O próprio projeto pode servir como um estudo de caso interessante de medida que se beneficiaria do uso de evidências no processo de decisão, justamente por tentar desenhar estratégias para a tomada de decisão de futuros criadores de políticas públicas.

78 KELLER, Carmen; MARKERT, Franziska; BUCHER, Tamara. Nudging product choices: the effect of position change on snack bar choice. Food Quality and Preference, v. 41, p. 41-43, 2015.

79 LEHNER, Matthias; MONT, Oksana; HEISKANEN, Eva. Nudging-A promising tool for sustainable consumption behaviour? Journal of Cleaner Production, v. 134, p. 166-177. 2016.

80 COSTA, Natalia Lacerda Macedo. "Nudge" como abordagem regulatória de prevenção à corrupção pública no Brasil. Revista de informação legislativa: RIL, v. 54, n. 214, p. 91-111, abr./jun. 2017. Disponível em: < http://www12.senado.leg.br/ril/edicoes/54/214/ ril_v54_n214_p91>. Acesso em: 27 julho 2018.

81 Informações disponíveis em <http://www.rio.rj.gov.br/web/fjg/exibeconteudo?id=8059802\#>. Acesso em: 28 julho 2018. 


\subsection{Aplicando evidências comportamentais a propostas de políticas públicas: análise de duas recomendações do PLS 488/2017}

Para finalizar nossa discussão, portanto, destacaremos duas recomendações feitas pelo projeto e como elas podem ser compreendidas à luz de evidências comportamentais. A primeira diz respeito às próprias estratégias sugeridas para a tomada de decisão. O PLS 488/2017 pode ser vinculado a um movimento maior de racionalização das decisões. Ao sugerir em seu artigo 17-B, inciso VIII, que os projetos apresentem "a formalização dos processos decisórios correlatos, incluindo o registro da motivação e do conjunto de evidências que embasam a escolha política" 82 está conectado, de alguma forma, a esse movimento mais amplo que busca racionalizar os processos decisórios dos poderes e atores públicos, seja por meio da AIL, seja por uma avaliação de política pública, esse último mais claramente especificado no guia de análise ex ante das políticas públicas.

A análise racionalista é uma "metodologia para recomendar alternativas de políticas para questões públicas usando técnicas tais quais análise de custo-benefício, de custo-efetividade, análise de risco e outros métodos quantitativos" ${ }^{83}$. No país, alguns dos bastiões desse movimento podem ser encontrados no IPEA e no Ministério do Planejamento e outros espaços governamentais ${ }^{84}$.

No PLS 488/2017, os elementos apontados como importantes a serem respeitados na proposição da política pública pelo projeto de lei (economicidade, a efetividade, a eficácia e a eficiência) são frutos da influência desse movimento de racionalização e "da política fiscal restritiva de gasto, adotada por vários governos", fazendo com que a eficiência fosse "vista como o principal objetivo de qualquer política pública, aliada à importância do fator credibilidade e à delegação das políticas públicas para instituições com 'independência’ política" ${ }^{85}$.

Também no guia de análise ex ante das políticas públicas, conseguimos vislumbrar a influência desse movimento de racionalização. O guia afirma que a

avaliação das políticas públicas deve começar no nascedouro, por meio da análise ex ante, a fim de verificar, fundamentalmente, se respondem a um problema bem delimitado e pertinente. Em função disso, observa-se se há um objetivo claro de atuação do Estado e se propõe um desenho que efetivamente possa ser alcançado.[...] Como a demanda da sociedade é crescente, o desafio do governo para esta e as próximas gerações não é apenas conter a expansão do gasto público mas também avaliar em que pontos ele é pouco produtivo, com o propósito de procurar fazer mais com menos recursos e priorizando a efetividade e a eficiência das políticas públicas. Nesse sentido, a análise ex ante pode contribuir para que as decisões alocativas sejam orientadas por critérios mais claros e transparentes, baseados em análises técnicas mais robustas. O fundamento da análise ex ante é orientar a decisão para que ela recaia sobre a alternativa mais efetiva, eficaz e eficiente. ${ }^{86}$

O movimento racionalista também costuma ser vinculado às políticas públicas baseadas em evidências. Seria racional o processo decisório que seguisse um "método sistemático" para chegar a uma decisão "eficiente e lógica". Assim, os tomadores de decisão públicos atingem resultados melhores quando "primeiro

82 BRASIL. Projeto de Lei Complementar do Senado n 488 de 2017 - Texto final. Acrescenta dispositivos à Lei Complementar $\mathrm{n}^{\circ} 95$, de 26 de fevereiro de 1998, com o intuito de estabelecer normas e diretrizes para encaminhamento de proposições legislativas que instituam políticas públicas, propiciando melhor responsabilidade gerencial na Administração Pública. Disponível em: <https:// legis.senado.leg.br/sdleg-getter/documento?dm=7326614\&disposition=inline>. Acesso em: 15 maio 2018.

83 Tradução livre de: "Rationalist policy analysis is a methodology for recommending policy alternatives to public issues using techniques such as cost-benefit analysis, cost-effectiveness, risk analysis and other quantitative methods.". SECCHI, Leonardo. Policy Analysis in Brazil: a comparison of rationalist and argumentative approaches. Journal of Comparative Policy Analysis: research and practice, v. 18, n. 1, p. 93, 2016.

84 SECCHI, Leonardo. Policy analysis in Brazil: a comparison of rationalist and argumentative approaches. Journal of Comparative Policy Analysis: Research and Practice, v. 18, n. 1, p. 95, 2016.

85 SOUZA, Celina. Políticas públicas: uma revisão da literatura. Sociologias, Porto Alegre, ano 8, n. 16, p. 34, jul/dez 2006.

86 BRASIL. Casa Civil da Presidência da República. Avaliação de políticas públicas: guia prático de análise ex ante. Casa Civil da Presidência da República, Instituto de Pesquisa Econômica Aplicada. Brasília: Ipea, 2018. v. 1. p. 11. 
estabelecem um objetivo", em seguida "exploram alternativas para alcançá-lo"; depois tentam prever as "consequências e a probabilidade de ocorrência" de cada uma das alternativas; e, então, escolhem "a opção que maximiza os potenciais benefícios ao menor custo ou risco". Assim, isso é racional porque estabelece um "conjunto padrão de procedimentos para a feitura de políticas" que levem sempre aos "meios mais eficientes de atingir o objetivo da política" ${ }^{87}$.

No entanto, o uso de evidências em geral nas políticas públicas, em vários de seus estágios, não deve estar restrito à modelagem de decisão imposta aos agentes públicos. Isso porque o uso de evidências deve ser requerido, inclusive, na escolha do processo de tomada de decisão. E o que se pode demonstrar é que "pesquisas empíricas sobre o processo de tomada de decisão" descobriram que nem sempre a negociação da política se dá através de "deliberações racionais e cálculos de custos e benefícios", e os tomadores de decisão e criadores de políticas públicas não são "necessariamente neutros ou competentes" 88.

Embora seja questionável que a teoria exija tanto assim dos tomadores de decisão, é fato que não se pode escolher a priori uma teoria sem antes validá-la por evidências, se se quer levar a sério a evidência científica nas políticas públicas.

O uso da Teoria da Escolha Racional no próprio movimento de políticas públicas baseadas em evidências levantou críticas. Sobretudo em seu espraiamento inicial entre os atores e práticos das políticas públicas, o uso de evidências em políticas públicas ensejou uma "versão ingênua", em que a tarefa de inserir evidências em políticas públicas seria a de fornecer um guia "racional" ou "objetivo" para a tomada de decisão, "sem se deixar levar pelas influências distorcidas da tradição, interesse privado, ideologia ou vieses pessoais daqueles que estão no poder" ${ }^{89}$. Assim, a teoria parece apontar para uma racionalidade que reduz a própria tomada de decisão e posterior produção da política pública para uma questão de "aplicar evidências robustas do 'que funciona' para promover de forma mais efetiva o alcance dos objetivos políticos estabelecidos" ${ }^{90}$.

Para responder a essa crítica, primeiramente, é importante compreender a diferença entre teorias prescritivas e descritivas da tomada de decisão. Tomada num sentido puramente instrumental, essa concepção de racionalidade nos parece adequada, já que ela não pressupõe que os indivíduos tomadores de decisão são movidos por objetivos racionais ou lógicos, mas apenas que devem tentar se concentrar nas evidências e tentar diminuir a influência dos elementos pessoais e ideológicos quando eles não forem aumentar a eficiência da política. Considerada dentro de uma perspectiva prescritiva, portanto, a adoção de racionalidade instrumental no processo de tomada de decisão parece bastante plausível.

87 Tradução livre de: “[...] argued that decision-makers attempt to follow a systematic method for arriving at logical, efficient decisions. [...] They argued that policy-makers achieved superior results when they first established a goal; explored alternative strategies for achieving it; attempted to predict its consequences and the likelihood of each occurring; and then chose the option which maximized potential benefits at least cost or risk [...].This model was "rational" in the sense that it prescribed a standard set of procedures for policymaking which were expected to lead in all circumstances to the choice of the most efficient means of achieving policy goals [...]”. HOWLETT, Michael; GIEST, Sarah. The policy-making process. In: ARARAL, Eduardo Araral Junior et al (Org.). Routledge handbook of public policy. Simultaneously published in the USA and Canada: Routledge, p. $20,2013$.

88 Tradução livre de trechos de: "Empirical research into decision-making processes, however, has discovered that political processes of bargaining and negotiation often outweigh "rational" deliberations and calculations of costs and benefits are subject to substantive and procedural limitations. Policy-makers were often found to be neither necessarily neutral nor competent and other models of the public policy decision-making processes have argued that this is not an accidental situation but rather an inherent and unavoidable characteristic of the policy-making exercise.”. HOWLETT, Michael; GIEST, Sarah. The policy-making process. In: ARARAL, Eduardo Araral Junior et al (Org.). Routledge Handbook of Public Policy. Canada: Routledge, p. $20,2013$.

89 Tradução livre de trechos de: “The term 'evidence-based policy' (EBP) has gained wide currency, but in the process has been subjected to substantial critique. In its naive version, best expressed by former Australian Prime MinisterKevin Rudd, the task of EBP is to provide a 'rational' or 'objective' guide to decision-making, unswayed by the distorting influences of tradition, private interest, ideology, or the personal biases of those in power (2008).” ARGYROUS, George. Evidence based policy: principles of transparency and accountability. Australian Journal of Public Administration, v. 71, n. 4, p. 457, 2012.

90 Tradução livre de trechos de: "The key proposition of this article, then, is that much of the contemporary debate about EBP is conducted within the confines of an 'instrumental rationality' that reduces the matter to a technical task of applying robust evidence of 'what works' to promote more effective achievement of given policy goals." SANDERSON, Ian. Complexity,'practical rationality'and evidence-based policy making. Policy \& politics, v. 34, n. 1, p. 127, 2006. 
Mesmo como instrumento, essa teoria deve ser matizada. As pessoas em geral nem sempre são capazes de acessar as melhores escolhas para elas, ou de chegar sem nenhuma preconcepção às evidências e soluções ao problema público analisado. Essa incapacidade decorre de vários mecanismos cognitivos que turvam a nossa avaliação da realidade, dos argumentos e das opções, chamados, convencionalmente, de "vieses" e "heurísticas". Os vieses são os erros sistemáticos e previsíveis que nosso sistema cognitivo comete ao avaliar alguma situação ${ }^{91}$. Já a heurística é um procedimento cognitivo por meio do qual buscamos dar uma resposta adequada a uma pergunta difícil, embora a resposta possa se mostrar imperfeita ou incompleta ${ }^{92}$.

O PLS 488/2017, quando afirma, no artigo 17-B, que o projeto de lei que institua política pública deve vir acompanhado de uma "formalização dos processos decisórios correlatos, incluindo o registro da motivação e do conjunto de evidências que embasam a escolha política", parece anuir a essa tentativa de uniformizar processos decisórios, ao mesmo tempo em que pode-se considerar que ele apele pela diminuição de ruídos cognitivos (como: tradição, interesse privado, ideologia e vieses). O mesmo é indicado no artigo 17-C, que afirma que o projeto deve apresentar uma AIL que indique "alternativas existentes para a solução da situação ou do problema identificado", "justificando-se a escolha da solução ou da providência contida no projeto proposto" 93 .

Os tomadores de decisão não podem ser considerados isentos desses mesmos vieses e heurísticas. Assim, quando se fala em racionalidade ou uso de evidências, devem-se considerar as fortes evidências que apontam num sentido contrário ao de uma racionalidade absoluta e neutra.

A segunda recomendação do projeto de lei que pode ser avaliada à luz das evidências comportamentais diz respeito à periodicidade da avaliação da política e a previsão de quais problemas podem ser gerados no futuro. O artigo 17-B afirma que a proposição legislativa deverá conter "a periodicidade da avaliação de desempenho das políticas públicas e a abordagem para solucionar conflitos e estabelecer formas de revisão, de modo a promover ajustes necessários", e o "o plano de gestão de riscos, identificando-se os principais problemas que podem surgir e as medidas mitigadoras para tratá-los" 94.

Esse foco na imaginação de cenários futuros pode auxiliar a diminuição de uma heurística e de um viés relacionados que podem acontecer quando um agente público está planejando uma intervenção qualquer na sociedade. A heurística de disponibilidade, que Kahneman chama de WYSIATI (what you see is all there is: o que você vê é tudo o que há), faz com que julguemos determinado evento como relevante ou determinada escolha como adequada simplesmente porque pensamos constantemente neles ou estamos submetidos a informações constantes sobre eles, e somos, por isso, capazes de criar uma narrativa coerente e crível. Por exemplo, as pessoas tendem a superestimar o risco de um acidente aéreo, porque as imagens são vívidas e a cobertura midiática é ampla. Essas informações nos levam a tirar conclusões sobre o risco de um acidente, embora na prática tenhamos informações insuficientes e não poderíamos, de forma sustentável, julgar esse risco ${ }^{95}$.

91 KAHNEMAN, Daniel. Rápido e devagar: duas formas de pensar. Tradução de Cássio de Arantes Leite. Rio de Janeiro: Objetiva, 2012. p. 10.

92 KAHNEMAN, Daniel. Rápido e devagar: duas formas de pensar. Tradução de Cássio de Arantes Leite. Rio de Janeiro: Objetiva, 2012. p. 127.

93 BRASIL. Projeto de Lei Complementar do Senado n 488 de 2017 - Texto final. Acrescenta dispositivos à Lei Complementar $n^{\circ} 95$, de 26 de fevereiro de 1998, com o intuito de estabelecer normas e diretrizes para encaminhamento de proposições legislativas que instituam políticas públicas, propiciando melhor responsabilidade gerencial na Administração Pública. Disponível em: <https:// legis.senado.leg.br/sdleg-getter/documento?dm=7326614\&disposition=inline >. Acesso em:15 maio 2018.

94 BRASIL. Projeto de Lei Complementar do Senado no 488 de 2017 - Texto final. Acrescenta dispositivos à Lei Complementar $n^{\circ} 95$, de 26 de fevereiro de 1998, com o intuito de estabelecer normas e diretrizes para encaminhamento de proposições legislativas que instituam políticas públicas, propiciando melhor responsabilidade gerencial na Administração Pública. Disponível em: <https:// legis.senado.leg.br/sdleg-getter/documento?dm=7326614\&disposition=inline > Acesso em: 15 maio 2018.

95 KAHNEMAN, Daniel. Rápido e devagar: duas formas de pensar. Tradução de Cássio de Arantes Leite. Rio de Janeiro: Objetiva, 2012, p. 111; THALER, Richard H.; SUNSTEIN, Cass R. Nudge: Improving decisions about health, wealth, and happiness. New Haven: Yale University Press, 2008. p. 24-25. 
Isso é especialmente aplicável quando o tomador de decisão está enfrentando um evento que acontecerá apenas uma vez. Nesse caso, não há dados confiáveis da probabilidade de que aquele evento ocorra, já que não se pode testar ou estudar a repetição desse evento no passado, então o tomador de decisão está num cenário completo de incertezas. Assim, quando estimamos a probabilidade de que algo ocorra, e esse algo é único, como é o caso de uma proposição de uma política pública inédita, há grandes chances de nos guiarmos pelas informações que nos parecem relevantes, sem ter claros mecanismos de correção e, geralmente, sem considerar as outras possíveis decorrências, aquelas que simplesmente não foram previstas porque nunca vivenciamos aquele evento ${ }^{96}$.

Relacionado a ela esta o viés de otimismo ou superconfiança. Por meio dele, temos uma confiança muito grande nas próprias decisões, sobretudo quando somos capazes de construir uma narrativa agradável que amarre as esparsas informações que temos sobre determinada situação ou escolha. Essa superconfiança atrapalha a avaliação sobre o futuro, uma vez que tendemos a superestimar o efeito positivo das nossas escolhas (ou até mesmo o efeito das nossas escolhas sobre o futuro, já que o acaso cumpre um papel maior do que costumamos atribuí-lo). Confundimos a facilidade de explicar o passado com a previsibilidade do futuro ${ }^{97}$.

Uma revisão de literatura sobre estudos do viés de otimismo demonstram, porém, que ao enfocar os riscos a que estariam submetidas, as pessoas tenderam a apresentar menos viés de otimismo, o que pode nos ajudar a pensar se o tomador de decisão pública não está também submetido a esse viés ${ }^{98}$. Não é difícil pensar que, ao propor uma estratégia, o tomador de decisão coloque grandes expectativas no sucesso desta, tanto por razões próprias de sua função quanto por razões pessoais como prestígio entre os pares e chance de ascensão profissional.

Ao obrigar o agente público a imaginar cenários futuros diversos, tanto de conflitos quanto de riscos possíveis decorrentes da implementação de dada política pública, o PLS 488/2017 pode estar estimulando o agente a considerar informações diversas das que se colocam salientes no momento, e que provavelmente levaram à escolha daquele problema como politicamente relevante. Assim, ele o leva a considerar que a ação imediata pode levar a decorrências não desejadas, além de ajustar as possibilidades efetivas de interferência no mundo e de solução absoluta dos problemas públicos. Imaginar cenários pessimistas diminui a superconfiança possível de determinado propositor de política pública.

Além disso, o próprio uso de evidências pode ajudar a evitar o que pode ser chamado de falácia do planejamento, quando planos "estão irrealisticamente próximos de hipóteses superotimistas" e "podem ser melhorados com uma consulta às estatísticas de casos semelhantes" ${ }^{99}$. Nesse caso, o otimismo exacerbado pode ser mitigado com o uso de probabilidades e com a consideração de experiências testadas anteriormente que sejam de mesma classe e devem ajudar a informar o agente público das chances de essa interferência na realidade ser mais adequada ${ }^{100}$.

Um estudo, por exemplo, cogitou que uma possível explicação para a demora na entrega na conclusão de megaprojetos de transportes nos EUA é justamente o viés de otimismo, com falsas expectativas sobre os benefícios do projeto, disponibilidade de orçamento e a capacidade de o projeto resolver o problema.

96 TVERSKY, Amos; KAHNEMAN, Daniel. Availability: A heuristic for judging frequency and probability. Cognitive psychology, v. 5, n. 2, p. 207-232, 1973.

97 KAHNEMAN, Daniel. Rápido e devagar. duas formas de pensar. Tradução de Cássio de Arantes Leite. Rio de Janeiro: Objetiva, 2012. p. 272-273.

98 HELWEG-LARSEN, Marie; SHEPPERD, James A. Do moderators of the optimistic bias affect personal or target risk estimates? a review of the literature. Personality and Social Psychology Review, v. 5, n. 1, p. 74-95, 2001.

99 KAHNEMAN, Daniel. Rápido e devagar: duas formas de pensar. Tradução de Cássio de Arantes Leite. Rio de Janeiro: Objetiva, 2012. p. 311.

100 KAHNEMAN, Daniel. Rápido e devagar: duas formas de pensar. Tradução de Cássio de Arantes Leite. Rio de Janeiro: Objetiva, 2012. p. 309. 
Assim, os tomadores de decisão são levados à falácia do planejamento ${ }^{101}$. Embora seja importante, é claro, considerar que há outras informações importantes na tomada de decisão, como possíveis interesses em superestimar um orçamento ou ter uma visão otimista das consequências como estratégia política e como uma decisão economicamente acertada ${ }^{102}$.

A mesma falácia do planejamento pode ser mitigada pela obrigação de constar um orçamento, que é o que está sendo expressamente requisitado pelo artigo 17-C do PLS 488/2017, e pela atribuição de responsabilidade, como disposto no artigo 17-B. Ao saber qual era o plano original, e quem era o responsável por cumpri-lo, abre-se a possibilidade de responsabilização quando as contas não estiverem batendo, uma forma interessante de melhorar a capacidade de planejamento dentro de uma organização em geral ${ }^{103}$.

Como o PLS 488/2017 se propõe a regular a proposição de políticas públicas que se utilizem de projetos de lei, é importante que ele esteja atento em buscar minimizar o efeito dos turvamentos de escolha (vieses e heurísticas) ou dos ruídos cognitivos (tradição, interesse privado, ideologia e vieses) da parte dos próprios agentes públicos.

\section{Considerações Finais}

As políticas públicas são a materialização do Estado e a forma por meio da qual ele responde a anseios sociais e interfere na realidade. Nesse sentido, as políticas públicas são aquilo que o governo deve entregar à sociedade, é o objetivo último de um governo legítimo.

A importância de controlar os gastos públicos não deve ser menosprezada. Os recursos são finitos, e o poder público tem a obrigação de ser responsável com o uso dos recursos, dentre eles o próprio orçamento disponível. Nesse sentido, os esforços do poder público de tornar a produção de políticas públicas fiscalmente responsável devem ser reconhecidos.

O PLS 488/2017 e o "guia prático de análise ex ante" de políticas públicas parecem indicar que o Estado brasileiro está se tornando cada vez mais atento às condições orçamentárias e aos limites que a realidade impõe àqueles que pretendem usar o Estado para alterar determinada realidade. A efetividade desse objetivo, porém, deve ser acompanhada de perto pelos cidadãos através de mecanismos de accountability e controle social, para que a edição dos textos normativos seja acompanhada de um impacto real na sociedade e nos poderes do Estado.

Apenas o controle de gastos, porém, não é capaz de levar a ação governamental a cumprir os objetivos de um Estado Democrático de Direito. Quando se aproveita do conhecimento produzido pela sociedade como um todo e aprende-se com as experiências anteriores, o resultado é um melhoramento gradual e cumulativo nas modificações concretas que o Estado faz.

O uso de evidências na formulação de políticas públicas pode aumentar a capacidade de ação do Estado, melhorando sua atuação e aprimorando o trabalho dos criadores de políticas públicas. O movimento de políticas públicas baseadas em evidências tem bastante força em outros países e cenários acadêmicos, e começa a surgir no contexto brasileiro. Na área da saúde pública, já há estudos interessantes que demonstram como

101 PLOTCH, Philip Mark. What's taking so long? identifying the underlying causes of delays in planning transportation megaprojects in the United States. Journal of Planning Literature, v. 30, n. 3, p. 282-295, 2015.

102 FLYVBJERG, Bent. Policy and planning for large-infrastructure projects: problems, causes, cures. Environment and Planning B: Planning and Design, v. 34, n. 4, p. 578-597, 2007.

103 BRASIL. Projeto de Lei Complementar do Senado n 488 de 2017 - Texto final. Acrescenta dispositivos à Lei Complementar $n^{\circ} 95$, de 26 de fevereiro de 1998, com o intuito de estabelecer normas e diretrizes para encaminhamento de proposições legislativas que instituam políticas públicas, propiciando melhor responsabilidade gerencial na Administração Pública. Disponível em: <https:// legis.senado.leg.br/sdleg-getter/documento?dm=7326614\&disposition=inline > Acesso em: 15 maio 2018; KAHNEMAN, Daniel. Rápido e devagar: duas formas de pensar. Tradução de Cássio de Arantes Leite. Rio de Janeiro: Objetiva, 2012. p. $312-314$. 
as evidências podem aprimorar a atuação do Estado nesse setor. Outra forma de aproximar as evidências das políticas que está crescendo no Brasil e no mundo é por meio das políticas reconhecidas como nudges. Assim, o PLS 488/2017 deve ser compreendido como uma forma de inserir o uso de evidências rigorosas e a reflexão cuidadosa do tomador de decisão que se proponha a instaurar ou modificar uma política pública, e como um estímulo para ampliar os debates acadêmicos sobre o movimento de práticas baseadas em evidências.

Mais especificamente, as evidências comportamentais podem auxiliar os criadores de políticas públicas. Elas podem ajudar na análise de impacto que a política pública terá em seu público-alvo e no entorno, trazendo à atenção dos agentes as consequências das suas ações e estratégias alternativas de alteração da realidade, como os nudges e os boosts.

$\mathrm{E}$ as ciências comportamentais podem ajudar, também, a compreender como as decisões são tomadas e como as políticas serão interpretadas pelos outros atores políticos e sociais relevantes, aumentando a efetividade do ator político e a capacidade de implementação. Nesse sentido, vincular a produção de projetos de lei a metas e mecanismos de decisão pode ajudar a diminuir os vieses e heurísticas que atrapalham a própria proposição das políticas.

O PLS 488/2017 abre espaço para que insiramos as evidências comportamentais no planejamento da ação governamental, como demonstrado. Caso aprovado, ele deve ser assumido pelos atores estatais e pelos atores acadêmicos e outros que estejam em condições de compreender e classificar de forma sistemática a realidade como um convite ao diálogo e à corresponsabilidade pela melhoria da atuação do Estado brasileiro.

\section{REFERÊNCIAS}

ALVAREZ, Adela Duarte. Elaboração Legislativa: aspectos gerais. Revista do Parlamento Paulista - RPP, São Paulo, v.2, n.3, p.112-123, jul./dez. 2012.

AMARAL, Gilberto Luiz do et al. Quantidade de normas editadas no Brasil: 28 anos da Constituição Federal de 1988. São Paulo: Instituto Brasileiro de Planejamento Tributário, 2016. Disponível em <https://ibpt. com.br/img/uploads/novelty/estudo/2603/QuantidadeDeNormas201628AnosCF.pdf>. Acesso em: 27 jul. 2018.

ANDRADE, Aparecida de Moura; SANTANA, Héctor Valverde. Avaliação de políticas públicas versus avaliação de impacto legislativo: uma visão dicotômica de um fenômeno singular. Revista Brasileira de Políticas Públicas, Brasília, v. 7, n. 3, p. 781-798, 2017.

ARGYROUS, George. Evidence based policy: principles of transparency and accountability. Australian Journal of Public Administration, v. 71, n. 4, p. 457-468, 2012.

BAHIA, Alexandre; NUNES, Dierle. Crise da Democracia Representativa: infidelidade partidária e seu reconhecimento judicial. Revista Brasileira de Estudos Políticos, v. 100, p. 57-84, 2010.

BLACK, Nick. Evidence based policy: proceed with care. British Medical Journal (BMJ), v. 323, n. 7307, p. 275, 2001.

BOGOSSIAN, André. Levando o orçamento a sério como instrumento de controle de políticas públicas. Revista Brasileira de Políticas Públicas, Brasilia, v. 5, n. 3, p. 178-198, 2015.

BONELL, Chris et al. One nudge forward, two steps back. British Medical Journal (BMJ), v. 342, n. 25, p. d401, jan. 2011.

BRASIL. Decreto $n^{0}$ 9.191, de $1^{\circ}$ de novembro de 2017. Estabelece as normas e as diretrizes para elaboração, redação, alteração, consolidação e encaminhamento de propostas de atos normativos ao Presidente da 
República pelos Ministros de Estado. Disponível em: < http://www.planalto.gov.br/CCIVil_03/_Ato20152018/2017/Decreto/D9191.htm\#art60>. Acesso em: 26 jul. 2018.

BRASIL. Emenda Constitucional n 95, de 15 de dezembro de 2016. Altera o Ato das Disposições Constitucionais Transitórias, para instituir o Novo Regime Fiscal, e dá outras providências. Disponível em: <http://www. planalto.gov.br/ccivil_03/constituicao/emendas/emc/emc95.htm>. Acesso em: 22 mar. 2018.

BRASIL. Constituição (1988). Constituição da República Federativa do Brasil de 1988. Disponível em <http:// www.planalto.gov.br/ccivil_03/constituicao/constituicao.htm>. Acesso em: 25 mar. 2018.

BRASIL. Lei Complementar n 95, de 26 de fevereiro de 1998. Dispõe sobre a elaboração, a redação, a alteração e a consolidação das leis, conforme determina o parágrafo único do art. 59 da Constituição Federal, e estabelece normas para a consolidação dos atos normativos que menciona. Disponível em: < http://www.planalto.gov. br/ccivil_03/leis/lcp/lcp95.htm>. Acesso em: 25 mar. 2018.

BRASIL. Projeto de Lei Complementar do Senado n 488 de 2017 - Texto preliminar. Acrescenta dispositivos à Lei Complementar $n^{\circ}$ 95, de 26 de fevereiro de 1998, com o intuito de estabelecer normas e diretrizes para encaminhamento de proposições legislativas que instituam políticas públicas, propiciando melhor responsabilidade gerencial na Administração Pública. Disponível em: < https://legis.senado.leg.br/sdleg-getter/doc umento?dm=7326614\&disposition=inline $>$ Acesso em: 15 maio 2018.

BRASIL. Projeto de Lei Complementar do Senado no 488 de 2017 - Texto final. Acrescenta dispositivos à Lei Complementar $\mathrm{n}^{\circ} 95$, de 26 de fevereiro de 1998, com o intuito de estabelecer normas e diretrizes para encaminhamento de proposições legislativas que instituam políticas públicas, propiciando melhor responsabilidade gerencial na Administração Pública. Disponível em: <https://legis.senado.leg.br/sdleg-getter/documento? $\mathrm{dm}=7326614 \&$ disposition=inline $>$ Acesso em: 15 maio 2018.

BRASIL. Casa Civil da Presidência da República. Avaliação de políticas públicas: guia prático de análise ex ante. Brasília: Ipea, 2018. v. 1

CLARENCE, Emma. Technocracy reinvented: the new evidence based policy movement. Public Policy and Administration, v. 17, n. 3, p. 1-11, July 1, 2002.

COSTA E SILVA, Vera Luiza et al. Bridging the gap between science and public health: taking advantage of tobacco control experience in Brazil to inform policies to counter risk factors for non-communicable diseases. Addiction, v. 108, n. 8, p. 1360-1366, 2013.

COSTA, Natalia Lacerda Macedo. "Nudge" como abordagem regulatória de prevenção à corrupção pública no Brasil. Revista de informação legislativa: RIL, v. 54, n. 214, p. 91-111, abr./jun. 2017. Disponível em: < http:// www12.senado.leg.br/ril/edicoes/54/214/ril_v54_n214_p91>. Acesso em: 27 jul. 2018.

DIAS, Maria Socorro de Araújo et al. Judicialização da saúde pública brasileira. Revista Brasileira de Políticas Públicas, Brasília, v. 6, n. 2, p. 132-145, 2016.

FARAH, Marta Ferreira Santos. An analysis of public policies in Brazil: from an unnamed practice to the institutionalization of the" public field". Revista de Administração Pública, v. 50, n. 6, p. 959-979, 2016.

FLYVBJERG, Bent. Policy and planning for large-infrastructure projects: problems, causes, cures. Environment and Planning B: Planning and Design, v. 34, n. 4, p. 578-597, 2007.

GRAY, J. A. Muir. Evidence-Based Public Health. In: TRINDER, Liz; REYNOLDS, Shirley (Org.). Evidence-based practice: a critical appraisal. Oxford: Blackwell, 2003.

GRÜNE-YANOFF, Till. Why behavioural policy needs mechanistic evidence. Economics \& Philosophy, v. 32, n. 3, p. 463-483, 2016.

GRÜNE-YANOFF, Till; HERTWIG, Ralph. Nudge versus boost: how coherent are policy and theory?. Minds and Machines, v. 26, n. 1-2, p. 149-183, 2016. 
HELWEG-LARSEN, Marie; SHEPPERD, James A. Do moderators of the optimistic bias affect personal or target risk estimates? A review of the literature. Personality and Social Psychology Review, v. 5, n. 1, p. 74-95, 2001.

HOWLETT, Michael. Policy analytical capacity and evidence-based policy-making: lessons from Canada. Canadian public administration, v. 52, n. 2, p. 153-175, 2009.

HOWLETT, Michael; GIEST, Sarah. The policy-making process. In: ARARAL, Eduardo Araral Junior et al (Org.). Routledge Handbook of Public Policy. Canada: Routledge, 2013. p. 17-28.

KAHNEMAN, Daniel. Rápido e devagar. duas formas de pensar. Rio de Janeiro: Objetiva, 2012.

KELLER, Carmen; MARKERT, Franziska; BUCHER, Tamara. Nudging product choices: the effect of position change on snack bar choice. Food Quality and Preference, v. 41, p. 41-43, 2015.

LEHNER, Matthias; MONT, Oksana; HEISKANEN, Eva. Nudging-A promising tool for sustainable consumption behavioura. Journal of Cleaner Production, v. 134, p. 166-177, 2016.

MENEGUIN, Fernando B. Avaliação de impacto legislativo no Brasil. Brasília: Senado Federal, Consultoria Legislativa, Textos para Discussão 70, de Março de 2010. Disponível em: <https://www12.senado.leg.br/ publicacoes/estudos-legislativos/tipos-de-estudos/textos-para-discussao/td-70-avaliacao-de-impacto-legislativo-no-brasil>. Acesso em: 25 abr. 2018.

MINTROM, Michael; WILLIAMS, Claire. Public policy debate and the rise of policy. In: ARARAL, Eduardo Araral Júnior et al (Org.). Routledge Handbook of Public Policy. Canada: Routledge, 2013. p. 3-16,

OLIVEIRA, Jussiely Cunha; BARRETO-FILHO, José Augusto. Políticas públicas em saúde embasadas em ciência "made in Brazill": um desafio para os arquivos brasileiros de cardiologia. Arq Bras Cardiol, v. 105, n. 3, p. 211-213, 2015.

PAWSON, Ray. Evidence-based policy: a realist perspective. London; Thousand Oaks; New Delhi: Sage, 2006.

PAWSON, Ray. Evidence-based policy: in search of a method. Evaluation, v. 8, n. 2, p. 157-181, 2002.

PLOTCH, Philip Mark. What's taking so long? Identifying the underlying causes of delays in planning transportation megaprojects in the United States. Journal of Planning Literature, v. 30, n. 3, p. 282-295, 2015.

REDDY, K. Srikanth; SAHAY, Seema. Voices of decision makers on evidence-based policy: a case of evolving TB/HIV co-infection policy in India. AIDS care, v. 28, n. 3, p. 397-400, 2016.

SALINAS, Natasha Schmitt Caccia. Avaliação Legislativa no Brasil: apontamentos para uma nova agenda de pesquisa sobre o modo de produção das leis. Revista Brasileira de Políticas Públicas, Brasília, v. 3, n. 2, 2013.

SANDERSON, Ian. Complexity, 'practical rationality' and evidence-based policy making. Policy \& politics, v. 34, n. 1, p. 115-132, 2006.

SECCHI, Leonardo. Policy Analysis in Brazil: a comparison of rationalist and argumentative approaches. Journal of Comparative Policy Analysis: Research and Practice, v. 18, n. 1, p. 88-101, 2016.

SECCHI, Leonardo. Políticas públicas: conceitos, esquemas de análise, casos práticos. São Paulo: Cengage Learning, 2010.

SOARES, Fabiana de Menezes. Legística e desenvolvimento: a qualidade da lei no quadro da otimização de uma melhor legislação. Revista da Faculdade de Direito da UFMG, Belo Horizonte, n. 50, p. 124-142, jan./ jul. 2007. Disponível em: <https://www.direito.ufmg.br/revista/articles/31.pdf>. Acesso em: 27 jul. 2018.

SODRÉ, Habacuque Wellington. As deficiências da atuação como fator de ativismo: hipertrofia e omissão legislativa. Uma análise da sociologia jurídica sobre o caso brasileiro de ativismo judicial. Direito Público, Porto Alegre, v. 8, n. 43, p. 160-194, jan./fev. 2012. 
SOUZA, Celina. Políticas públicas: uma revisão da literatura. Sociologias, Porto Alegre, ano 8, n. 16, p. 20-45, jul./dez. 2006.

SUNSTEIN, Cass R.; REISCH, Lucia A.; RAUBER, Julius. A worldwide consensus on nudging? not quite, but almost. Regulation \& Governance, v. 12, n. 1, p. 3-22, 2018.

THALER, Richard H.; SUNSTEIN, Cass R. Nudge: Improving decisions about health, wealth, and happiness. New Haven: Yale University Press, 2008.

TRINDER, Liz. Introduction: the context of evidence-based practice. In: TRINDER, Liz; REYNOLDS, Shirley (Org.). Evidence-based practice: a critical appraisal. Oxford: Blackwell, 2003.

TVERSKY, Amos; KAHNEMAN, Daniel. Availability: a heuristic for judging frequency and probability. Cognitive psychology, v. 5, n. 2, p. 207-232, 1973.

WIZIACK, Júlio; PRADO, Maeli. Governo deu R \$ 173 bi em subsídios a programas sem efeitos, diz estudo. São Paulo. Folha de São Paulo. Publicado em 22 de julho de 2018. Disponível em: <https://www1.folha. uol.com.br/mercado/2018/07/governo-deu-r-173-bi-em-subsidios-a-programas-sem-efeitos-diz-estudo. shtml>. Acesso em: 26 jul. 2018. 
Para publicar na revista Brasileira de Políticas Públicas, acesse o endereço eletrônico www.rbpp.uniceub.br

Observe as normas de publicação, para facilitar e agilizar o trabalho de edição. 